CDD: 111.2

\title{
UNIVERSALES ESTRUCTURALES
}

JOSÉ TOMÁS ALVARADO

Instituto de Filosofía

Pontificia Universidad Católica de Valparaíso

Av. El Bosque 1290

Viña del Mar

Chile

jose.alvarado.m@ucv.cl

Received: 29.01.2009; Revised: 17.02.20II; Accepted: 31.05.20II

\begin{abstract}
The work presents the concept of a structural universal and the criticisms that have been leveled against it. A structural universal is a property had by an individual due to the nature of its proper parts and due to the relations obtaining between those parts. Mellor has argued that there is no reason to accept such universal in addition to the basic universals that compose them. David Lewis has argued -on the other handthat it has not been satisfactorily explained how universals are composed by other universals. The composition by which a structural universal is given cannot be a settheoretical construction or a mereological sum. Several proposals to explain the nature of structural universals are discussed. Finally it is argued that a structural universal should be understood as a complexion of higher-order universals.
\end{abstract}

Keywords: Universals. Structural Universals. Composition. High-Order Universals.

Un universal estructural es un tipo de propiedad compleja que caracteriza cómo es un objeto mediante la caracterización de cómo son sus partes y qué relaciones existen entre éstas partes ${ }^{1}$. Hay diversas funciones teóricas que estos universales estructurales deberían cumplir y que han motivado su postulación: la concepción de las leyes naturales

${ }^{1}$ Cf. para explicaciones generales de la noción, Armstrong (1978, 1989 y 1997).

Manuscrito - Rev. Int. Fil., Campinas, v. 34, n. 2, pp. 471-521, jul.-dez. 2011. 
como relaciones de necesitación entre universales ${ }^{2}$, una concepción de los mundos posibles como propiedades ${ }^{3}$ o el permitir la posibilidad epistémica- de que la realidad posea un grado de complejidad infinita 4 . La postulación de universales estructurales, sin embargo, se ha enfrentado a diversas críticas. Por un lado, filósofos como David Lewis han sostenido que no se ha hecho todavía inteligible cómo es que un universal podría estar "compuesto" por otros universales ${ }^{5}$. Por otro lado, filósofos como Hugh Mellor han sostenido que no hay motivos suficientes para justificar su aceptación ${ }^{6}$. Las críticas han motivado diversas estrategias de respuesta, en particular, a las objeciones de Lewis. En este trabajo se pretenden explorar y evaluar críticamente estas estrategias de respuesta. La motivación fundamental para efectuar este examen es el interés por comprender las funciones teóricas indicadas arriba de los universales estructurales en diversas áreas. Para esto es indispensable una comprensión más detallada de qué es un universal estructural, si es que hay tal cosa y, luego, cómo es que un universal de este tipo podría entrar a constituir, por ejemplo, mundos posibles, leyes naturales o estructuras de una complejidad infinita. Siendo todas éstas cuestiones metafísicas sustantivas que requieren atención por sí mismas, la dilucidación de qué sean los universales estructurales es un paso indispensable para la adjudicación ulterior de tales cuestiones.

En este trabajo, por lo tanto, se explicará, en primer lugar y al menos de un modo preliminar, qué es un universal estructural. En

\footnotetext{
${ }^{2}$ Cf. Tooley (1977, 1987); Dretske (1977) y Armstrong (1983).

3 Cf. Stalnaker (2003, pp. 25-39), Forrest (1986a), Bigelow and Pargetter (1990), Alvarado (2006).

${ }^{4}$ Cf. Armstrong (1978, pp. 67-68; 1997, p. 33); Una explicación general de los diferentes motivos que podrían aducirse para aceptar universales estructurales puede encontrarse en Lewis (1999, p. 78-107) (publicado originalmente en Australasian Journal of Philosophy 64 (1986), pp. 25-46), especialmente pp. 82-87.

${ }^{5}$ Cf. Lewis (1999).

${ }^{6}$ Cf. Mellor (1995, pp. 193-199).
}

Manuscrito - Rev. Int. Fil., Campinas, v. 34, n. 2, pp. 471-521, jul.-dez. 2011. 
segundo lugar, se indicarán las diversas críticas ya sea a la inteligibilidad de la noción de universal estructural, ya sea a la necesidad de su postulación. Por último, se examinarán de manera crítica las diferentes estrategias de respuesta a las dificultades apuntadas, para indicar finalmente una hipótesis sobre cómo podrían ser comprendidos. En todo este examen no se pondrá en cuestión la existencia de universales y no se supondrá para estos universales una naturaleza específica, en particular, el examen será neutral entre concepciones que exigen que todo universal se encuentre instanciado y concepciones que admiten universales no instanciados ${ }^{7}$.

\section{1. ¿Qué es un universal estructural?}

En la caracterización que hace Armstrong de los universales estructurales, estos son caracterizados como universales complejos anhomeómeros no emergentes que pueden poseer una estructura relacional o no relacional $^{8}$. Para explicar esta caracterización será

7 Fácilmente puede verse, sin embargo, que otras teorías metafísicas de propiedades tienen que enfrentar problemas semejantes. Un defensor de tropos, por ejemplo, también tendrá que contestar de algún modo si el tropo de ser una molécula de agua es un tropo diferente que debe postularse además de los tropos de ser átomos de oxígeno y de hidrógeno con determinados tropos relacionales de enlace entre ellos. El defensor de tropos deberá explicar, en efecto, qué son las estructuras de acuerdo a su metafísica y cómo es que un tropo está compuesto de otros tropos. No veo que la situación sea tanto más sencilla para un defensor del nominalismo de semejanza. Si él pretende eliminar las propiedades simplemente con clases de objetos semejantes tomando la relación de semejanza como un primitivo- tendrá también que explicar cómo es que se relacionan entre sí, por ejemplo, la clase de semejanza que constituye la propiedad de ser una molécula de agua y la clase de semejanza de ser un átomo de oxígeno. Las indagaciones que se hagan aquí respecto de universales, por lo tanto, serán de utilidad mutatis mutandis para estas otras concepciones metafísicas.

${ }^{8}$ Cf. Armstrong (1978 pp. 67-71).

Manuscrito - Rev. Int. Fil., Campinas, v. 34, n. 2, pp. 471-521, jul.-dez. 2011. 
conveniente exponer, en primer término, qué ha de entenderse por una propiedad compleja:

Si una propiedad es compleja, entonces tiene partes. Estas partes son propiedades $\mathrm{y} / \mathrm{o}$ relaciones. Las llamaremos constituyentes de la propiedad compleja. Una propiedad compleja puede o no tener constituyentes últimos, i.e. propiedades simples y relaciones simples 9 .

De algún modo, una propiedad compleja es una propiedad que tiene como "partes" a otras propiedades, por lo que la instanciación de la primera propiedad implica la instanciación de las segundas. ¿Cómo debe entenderse este "ser parte" de una propiedad? Intuitivamente pareciera que dadas ciertas propiedades "básicas" $P_{m}$ y $P_{n}$ nada impediría realizar sobre éstas operaciones booleanas $\left[\mathrm{P}_{\mathrm{m}} \wedge \mathrm{P}_{\mathrm{n}}\right],\left[\mathrm{P}_{\mathrm{m}} \vee\right.$ $\left.\mathrm{P}_{\mathrm{n}}\right]$ y $\left[\neg \mathrm{P}_{\mathrm{m}}\right]$. Pareciera también que las propiedades que resultan de estas operaciones de conjunción, disyunción y negación pueden ser fácilmente vertidas en teoría de modelos, pues si la extensión asignada a $\mathrm{P}_{\mathrm{m}}$ es $\left\{\mathrm{x}: \mathrm{P}_{\mathrm{m}} \mathrm{x}\right\}$ y la extensión asignada a $\mathrm{P}_{\mathrm{n}}$ es $\left\{\mathrm{x}: \mathrm{P}_{\mathrm{n}} \mathrm{x}\right\}$, entonces la extensión de $\left[\mathrm{P}_{\mathrm{m}} \wedge \mathrm{P}_{\mathrm{n}}\right]$ es $\left\{\mathrm{x}: \mathrm{P}_{\mathrm{m}} \mathrm{x}\right\} \cap\left\{\mathrm{x}: \mathrm{P}_{\mathrm{n}} \mathrm{x}\right\}=\left\{\mathrm{x}:\left(\mathrm{P}_{\mathrm{m}} \mathrm{x} \wedge \mathrm{P}_{\mathrm{n}} \mathrm{x}\right)\right\}$, la extensión de $\left[\mathrm{P}_{\mathrm{m}} \vee \mathrm{P}_{\mathrm{n}}\right]$ es $\left\{\mathrm{x}: \mathrm{P}_{\mathrm{m}} \mathrm{x}\right\} \cup\left\{\mathrm{x}: \mathrm{P}_{\mathrm{n}} \mathrm{x}\right\}=\left\{\mathrm{x}:\left(\mathrm{P}_{\mathrm{m}} \mathrm{x} \vee \mathrm{P}_{\mathrm{n}} \mathrm{x}\right)\right\}$ y la extensión de $\left[\neg \mathrm{P}_{\mathrm{m}}\right]$ es $\left\{\mathrm{x}: \neg \mathrm{P}_{\mathrm{m}} \mathrm{x}\right\}$. Una propiedad "compleja" es una propiedad que, de alguna manera, ha de surgir por estas operaciones $u$ otras. Una propiedad que no es compleja es una propiedad simple. Tal como se verá, en efecto, las operaciones booleanas de conjunción, disyunción y negación no son suficientes para configurar universales estructurales.

Armstrong dedica bastante espacio a rechazar la existencia de universales negativos y disyuntivos, pero sí acepta la existencia de universales conjuntivos ${ }^{10}$, con tal de que tengan positivamente instancias. Los universales disyuntivos y negativos parecen innecesarios en una concepción de propiedades "escasas" y no "abundantes", en la

\footnotetext{
${ }_{9}^{9}$ Armstrong (1978, p. 67).

${ }^{10}$ Cf. Armstrong (1978, pp. 19-42).
}

Manuscrito - Rev. Int. Fil., Campinas, v. 34, n. 2, pp. 471-521, jul.-dez. 2011. 
que la cuestión de qué universales existan no es algo que pueda decidirse a priori, sino que requiere de indagación empírica. Lewis tampoco pone dificultades a los universales conjuntivos, pues la operación de conjunción satisfaría los axiomas de mereología estándar. Lewis, en efecto, rechaza los universales estructurales básicamente porque no acepta formas de composición que no sean o las construcciones conjuntistas o las mereológicas, tal como se explicará. $\mathrm{Al}$ poder entenderse los universales conjuntivos como sumas mereológicas quedan liberados de las sospechas que pesan sobre formas más complejas de estructuración ${ }^{11}$. Nótese, sin embargo, que los universales conjuntivos de que se habla aquí son la propiedad de instanciar un mismo individuo, por ejemplo, $\mathrm{P}_{\mathrm{m}}$ y $\mathrm{P}_{\mathrm{n}}$. Sólo puede haber "conjunción" de propiedades con la misma adicidad. Para constituir propiedades estructurales se requiere un mecanismo para generar propiedades $(\mathrm{r}+\mathrm{s})$-ádicas dadas una propiedad $\mathrm{r}$-ádica y una propiedad s-ádica.

La distinción entre propiedades simples y complejas es ortogonal a la distinción entre propiedades homeómeras y anhomeómeras. Una propiedad es "homeómera" si todas las partes de

11 Cf. Lewis (1999, p. 100, nota 21). Los axiomas de mereología son los siguientes, tomando ' $<$ ' como "ser una parte propia de" (esto es, ser parte de algo y no ser idéntico a él), 'l' como "ser disjunto de" (esto es, no tener alguna parte en común) y ' $O$ ' como "estar sobrelapado con" (esto es, tener alguna parte impropia en común): (i) $(\mathrm{x}<\mathrm{y}) \rightarrow \neg(\mathrm{y}<\mathrm{x})$; (ii) $((\mathrm{x}<\mathrm{y}) \wedge(\mathrm{y}<\mathrm{z})) \rightarrow(\mathrm{x}$ $<\mathrm{z}$ ); (iii) $(\mathrm{x}<\mathrm{y}) \rightarrow \exists \mathrm{z}((\mathrm{z}<\mathrm{y}) \wedge(\mathrm{z} \mid \mathrm{x}))$; $\mathrm{y}$ (iv) $(\exists \mathrm{x} F \mathrm{x}) \rightarrow \exists \mathrm{x} \forall \mathrm{y}((\mathrm{y} \circ \mathrm{x}) \leftrightarrow \exists \mathrm{z}$ $(\mathrm{Fz} \wedge(\mathrm{y} \circ \mathrm{z})))$. La relación de "ser una parte propia de" queda caracterizada en estos axiomas como una relación: (i) antisimétrica; (ii) transitiva; (iii) tal que si $\mathrm{x}$ es parte propia de $\mathrm{y}$, entonces debe haber un $\mathrm{z}$ disjunto de $\mathrm{x}$ que sea también parte propia de y; y (iv) tal que si hay algo que sea F (para un 'F' cualquiera), entonces hay un $\mathrm{x}$ tal que un y cualquiera está sobrelapado con $\mathrm{x}$ si y sólo si hay un z que cae bajo F con el que y está sobrelapado (para una explicación de estos postulados, cf. Simons (1987), especialmente pp. 9-45). Para el caso de los universales conjuntivos, el "ser parte impropia de" debería tomarse como el constituir un universal conformado por la conjunción de $n$ propiedades.

Manuscrito - Rev. Int. Fil., Campinas, v. 34, n. 2, pp. 471-521, jul.-dez. 2011. 
aquel individuo que la instancia instancian la misma propiedad. Esto es, una propiedad homeómera $\mathrm{P}$ debe satisfacer que ${ }^{12}$ :

$$
\square \forall \mathrm{x} \square[\mathrm{Px} \rightarrow \forall \mathrm{y}((\mathrm{y}<\mathrm{x}) \rightarrow \mathrm{Py})]
$$

Aquí ' $<$ ' es "ser una parte propia de". Se han añadido operadores modales a la formulación de Armstrong. Una propiedad anhomeómera es una propiedad que no es homeómera. Una propiedad anhomeómera P es, por lo tanto, una propiedad que satisface:

$$
\diamond \exists \mathrm{x} \diamond[\mathrm{Px} \wedge \exists \mathrm{y}((\mathrm{y}<\mathrm{x}) \wedge \neg \mathrm{Py}]
$$

Esto es, una propiedad $\mathrm{P}$ es anhomeómera en caso de que tenga al menos una instancia que caiga bajo $\mathrm{P}$, pero que tenga una parte que no caiga bajo $\mathrm{P}$.

Ejemplos de propiedades homeómeras serían "tener masa" o "tener longitud". Parece obvio, en efecto, que un objeto que tenga masa habrá de tener partes que también tienen masa. La propiedad homeómera aquí es la propiedad determinable de "tener masa" y no la propiedad determinada de "tener una masa de $n$ gramos"13, pues un

\footnotetext{
${ }^{12}$ Agradezco especialmente aquí las observaciones de un referee anónimo que me han salvado de un error.

13 Para esta distinción cf. Armstrong (1978, pp. 111-113). Una propiedad determinable es una propiedad genérica, mientras que una propiedad determinada es una propiedad específica dentro de su género. Vale que (a) si algo instancia una propiedad determinada, entonces debe instanciar la propiedad determinable respectiva; (b) si algo instancia una propiedad determinable, entonces debe instanciar alguna de las propiedades determinadas que caen bajo ella; y (c) ningún objeto puede instanciar simultáneamente dos propiedades determinadas que caen bajo el mismo determinable. Armstrong rechaza que las determinables sean realmente propiedades (cf. Armstrong (1978, pp. 117-120)), pues todas las funciones explicativas que se atribuyen a los universales son cumplidas por los universales determinados.
}

Manuscrito - Rev. Int. Fil., Campinas, v. 34, n. 2, pp. 471-521, jul.-dez. 2011. 
objeto que tenga una masa de $n$ gramos tendrá partes con masas menores que $n$ (y que sumen todas ellas $n$ gramos). Una propiedad homeómera puede ser simple o compleja. En efecto, si la propiedad de tener masa y la propiedad de tener longitud son homeómeras, entonces la propiedad $[\lambda \mathrm{x}((\mathrm{x}$ tiene masa $) \wedge(\mathrm{x}$ tiene longitud $))]$ es también homeómera.

Interesa aquí considerar las propiedades anhomeómeras. Una propiedad anhomeómera S es estructural, indica Armstrong, cuando:

Las partes propias de los particulares que poseen $\mathrm{S}$ tienen cierta propiedad o propiedades, $\mathrm{T}$... no idénticas con $\mathrm{S}$ y este estado de cosas es, en parte al menos, constitutivo de S. ${ }^{14}$

No toda propiedad anhomeómera es estructural, pues podría darse una propiedad tal que no esté "constituida" por el estado de cosas de encontrarse las partes del objeto que instancia tal propiedad cayendo bajo ciertas propiedades y relaciones. Una propiedad anhomeómera no estructural es una propiedad emergente. Aunque aquí puede resultar todavía oscuro en qué consiste el que la posesión de cierta propiedad $\mathrm{P}$ "consista" en el hecho de que las partes del objeto que instancia $\mathrm{P}$ poseen otras propiedades $\mathrm{Q}_{1}, \ldots, \mathrm{Q}_{\mathrm{n}}$, puede decirse de manera general que una propiedad $\mathrm{P}$ es estructural si se satisface que, para algún $n \mathrm{y}$ algunas propiedades $\mathrm{Q}_{1}, \mathrm{Q}_{2}, \ldots, \mathrm{Q}_{\mathrm{n}}$ :

$$
\begin{aligned}
& \square \forall \mathrm{x} \square\left[\mathrm { Px } \leftrightarrow \exists \mathrm { y } _ { 1 } \exists \mathrm { y } _ { 2 } \ldots \exists \mathrm { y } _ { \mathrm { n } } \left(\left(\mathrm{y}_{1}<\mathrm{x}\right) \wedge\left(\mathrm{y}_{2}<\mathrm{x}\right) \wedge \ldots \wedge\left(\mathrm{y}_{\mathrm{n}}<\mathrm{x}\right)\right.\right. \\
& \left.\left.\wedge \mathrm{Q}_{1 \mathrm{y}_{1}} \wedge \mathrm{Q}_{2} \mathrm{y}_{2} \wedge \ldots \wedge \mathrm{Q}_{\mathrm{n} \mathrm{y}_{\mathrm{n}}}\right)\right]
\end{aligned}
$$

Esto es, si algo satisface una propiedad anhomeómera estructural P, entonces tendrá partes propias $\mathrm{y}_{1}, \mathrm{y}_{2}, \ldots, \mathrm{y}_{\mathrm{n}}$ cayendo bajo las propiedades $\mathrm{Q}_{1}, \mathrm{Q}_{2}, \ldots, \mathrm{Q}_{\mathrm{n}}$. Y, por otro lado, si un objeto posee partes propias $\mathrm{y}_{1}, \mathrm{y}_{2}, \ldots, \mathrm{y}_{\mathrm{n}}$ que caen bajo las propiedades $\mathrm{Q}_{1}, \mathrm{Q}_{2}, \ldots, \mathrm{Q}_{\mathrm{n}}$, entonces ese objeto cae bajo la propiedad estructural P. Como se trata

${ }^{14}$ Armstrong (1978, p. 69).

Manuscrito - Rev. Int. Fil., Campinas, v. 34, n. 2, pp. 471-521, jul.-dez. 2011. 
de una propiedad anhomeómera, basta que al menos una de $\mathrm{Q}_{1}, \mathrm{Q}_{2}, \ldots$, $\mathrm{Q}_{\mathrm{n}}$ sea diferente de $\mathrm{P}$ (pues, de otro modo, sería homeómera). Una propiedad anhomeómera, por otro lado, cuenta como "emergente" si y sólo si no se satisface (3). Como (3) es un bicondicional cuantificado universalmente, es falso en el caso de que exista al menos un objeto que, o bien $\left[\mathrm{Px} \wedge \forall \mathrm{y}_{1} \forall \mathrm{y}_{2} \ldots \forall \mathrm{y}_{\mathrm{n}}\left(\neg\left(\mathrm{y}_{1}<\mathrm{x}\right) \vee \neg\left(\mathrm{y}_{2}<\mathrm{x}\right) \vee \ldots \vee \neg\left(\mathrm{y}_{\mathrm{n}}<\right.\right.\right.$ $\left.\mathrm{x}) \vee \neg \mathrm{Q}_{1} \mathrm{y}_{1} \vee \neg \mathrm{Q}_{2} \mathrm{y}_{2} \vee \ldots \vee \neg \mathrm{Q}_{\left.\mathrm{n} \mathrm{y}_{\mathrm{n}}\right)}\right]$, o bien $\left[\neg \mathrm{Px} \wedge \exists \mathrm{y}_{1} \exists \mathrm{y}_{2} \ldots \exists \mathrm{y}_{\mathrm{n}}\left(\left(\mathrm{y}_{1}<\right.\right.\right.$ $\left.\left.\mathrm{x}) \wedge\left(\mathrm{y}_{2}<\mathrm{x}\right) \wedge \ldots \wedge\left(\mathrm{y}_{\mathrm{n}}<\mathrm{x}\right) \wedge \mathrm{Q}_{1 \mathrm{y}_{1}} \wedge \mathrm{Q}_{2} \mathrm{y}_{2} \wedge \ldots \wedge \mathrm{Q}_{\mathrm{n}} \mathrm{y}_{\mathrm{n}}\right)\right]$. Una propiedad estructural $\mathrm{P}$ tiene una cierta base constituida por el estado de cosas consistente en que las partes del objeto en cuestión poseen tales y cuales propiedades. Una propiedad es emergente cuando, o bien el objeto en cuestión posee tal propiedad, aunque la base no se dé, o bien cuando el darse de la base no sea garantía de que se poseerá la propiedad ${ }^{15}$. Una propiedad emergente puede ser simple o compleja (si es que, por ejemplo, es conjuntiva).

Las propiedades estructurales se distinguen, de acuerdo a Armstrong, entre propiedades con una estructura relacional y propiedades sin una estructura relacional. Una propiedad con estructura relacional es una propiedad que "consiste" en el hecho de que hay partes propias instanciando tales y cuales propiedades y que poseen cierta relación o relaciones entre sí. Otras propiedades estructurales no exigen la existencia de relaciones específicas entre las partes en cuestión. Por ejemplo, la propiedad de tener una masa de $n$ gramos es la

15 Debe recordarse aquí que una propiedad emergente es una propiedad anhomeómera, por lo que debe tener al menos una instanciación posible en que al menos una parte del objeto que la ejemplifica no instancia la misma propiedad. Tampoco podría ser una propiedad emergente una propiedad instanciada sólo por objetos atómicos (esto es, sin partes). El término "emergente" ha tenido, desgraciadamente, un uso bastante fluctuante. Aquí se estará a la caracterización indicada, pero debe notarse que, por ejemplo, en filósofos como C. D. Broad una propiedad "emergente" es, más bien, lo que se va a caracterizar como una propiedad estructural relacional (cf. Broad (1999)).

Manuscrito - Rev. Int. Fil., Campinas, v. 34, n. 2, pp. 471-521, jul.-dez. 2011. 
propiedad de tener algo partes propias cada una de las cuales tiene una masa de $(n-m)$ gramos (cada una con un $m$ apropiado), tales que sumen todas ellas exactamente $n$ gramos. No se exige aquí ningún tipo de configuración especial entre las partes del objeto que tiene $n$ gramos aparte del hecho, claro está, de que conformen todas esas partes un todo. Si se admiten sumas mereológicas irrestrictas -algo que hacen filósofos como Armstrong o Lewis- entonces las partes en cuestión podrían encontrarse en rincones opuestos del universo o separados por eones de distancia ${ }^{16}$. Por contraste, algo es una molécula de agua si y sólo si sus átomos componentes de hidrógeno y oxígeno poseen los enlaces químicos pertinentes. Dos átomos de hidrógeno en un rincón del universo y un átomo de oxígeno en el rincón opuesto no conforman una molécula de agua. Una propiedad estructural relacional debería satisfacer, entonces:

$$
\begin{aligned}
& \square \forall \mathrm{x} \square\left[\mathrm { Px } \leftrightarrow \exists \mathrm { y } _ { 1 } \exists \mathrm { y } _ { 2 } \ldots \exists \mathrm { y } _ { \mathrm { n } } \left(\left(\mathrm{y}_{1}<\mathrm{x}\right) \wedge\left(\mathrm{y}_{2}<\mathrm{x}\right) \wedge \ldots \wedge\left(\mathrm{y}_{\mathrm{n}}<\mathrm{x}\right)\right.\right. \\
& \left.\left.\wedge \mathrm{Q}_{1} \mathrm{y}_{1} \wedge \mathrm{Q}_{2} \mathrm{y}_{2} \wedge \ldots \wedge \mathrm{Q}_{\mathrm{n}} \mathrm{y}_{\mathrm{n}} \wedge \mathrm{R}_{1} \mathrm{y}_{2} \ldots \mathrm{y}_{\mathrm{n}}\right)\right]
\end{aligned}
$$

Mientras tanto, en una propiedad estructural no relacional puede omitirse que $\left[\mathrm{Ry}_{1} \mathrm{y}_{2} \ldots \mathrm{y}_{\mathrm{n}}\right]$. Podría aquí objetarse que comoquiera que vengan dadas las partes de un objeto habrá relaciones entre ellos. Al menos esas partes serán tales que conformarán una suma mereológica,

16 Por supuesto, esta situación varía si es que se imponen restricciones sobre las sumas mereológicas. Muchos filósofos han rechazado que para cualesquiera dos objetos $\mathrm{x}$ e y deba admitirse un tercer objeto $[\mathrm{x}+\mathrm{y}]$. En este caso, cualesquiera que sean los requerimientos adicionales que sean añadidos, ellos seguramente implicarán la existencia de relaciones sustantivas entre las partes que componen la suma. En este caso no habría universales estructurales no relacionales, pues - de entrada- si se da una suma mereológica es porque ya hay relaciones ontológicamente sustantivas entre las partes. Todo universal estructural debería ser relacional por definición. Para una discusión del principio de sumas irrestrictas, cf. Simons (1987, pp. 108-112); van Inwagen (1990, pp. 21-97).

Manuscrito - Rev. Int. Fil., Campinas, v. 34, n. 2, pp. 471-521, jul.-dez. 2011. 
esto es, lo menos que puede suponerse de tales partes es que sean partes y, por lo tanto, se encuentren entre sí en la relación de conformar un todo. La relación de conformar un todo es una relación, por lo que toda propiedad estructural debe tomarse como relacional. Lo que sucede aquí, sin embargo, es que en concepciones de propiedades "escasas" como la defendida por Armstrong sólo se admitirán como propiedades y relaciones aquellas entidades que la ciencia admite como efectuando una tarea causal-explicativa. No todo predicado debe ser correlacionado con una propiedad o relación. Así, en este caso, se podría sostener que hay un predicado "conformar un todo", pero no hay una relación auténtica que pueda ser correlacionada con tal predicado ${ }^{17}$.

Podría sostenerse que el hecho de que algo instancie una propiedad estructural $\mathrm{P}$ es superveniente al hecho de que sus partes instancien tales y cuales propiedades y relaciones. En general, los hechos del tipo A son supervenientes a los hechos del tipo B si y sólo si toda variación en cuanto a qué hechos $\mathrm{A}$ sean efectivos va acompañada de una variación en cuanto a qué hechos $B$ sean efectivos ${ }^{18}$. En este caso, si un objeto posee la propiedad estructural $\mathrm{P}$ y otro objeto no posee la propiedad estructural, esta diferencia debe hallarse

${ }_{17}$ Para la relación entre predicados y propiedades, cf. Armstrong (1978, pp. 718, pp. 43-59); para las relaciones en particular, ibidem, pp. 75-94.

${ }_{18}$ De manera equivalente, se puede sostener que los hechos del tipo A son supervenientes a los hechos del tipo B si y sólo si, si se da una configuración idéntica de hechos del tipo $B$, entonces tendrá que darse una configuración idéntica de hechos del tipo A. La relación de superveniencia que se indica entre una propiedad estructural y su base es una superveniencia fuerte y local. Esto es, se trata de una superveniencia en la que han de compararse instanciaciones de una propiedad en diferentes mundos posibles y, por otro lado, se considerarán como respectos relevantes para la comparación los hechos "locales" sobre las bases respectivas y no la distribución completa de hechos en diferentes mundos posibles. Para estas distinciones, cf. Kim (1993, pp. 5378 y pp. 79-91).

Manuscrito - Rev. Int. Fil., Campinas, v. 34, n. 2, pp. 471-521, jul.-dez. 2011. 
correlacionada con una diferencia en cuanto a qué propiedades y relaciones instancien las partes de los objetos respectivos. Es peculiar, sin embargo, de una propiedad estructural que la covariación debe ser simétrica entre la base y los hechos "dependientes". Como aquello en que consiste tener $\mathrm{x}$ una propiedad $\mathrm{P}$ es que las partes de $\mathrm{x}$ posean ciertas propiedades y relaciones, siempre que se dé una configuración idéntica de partes con tales propiedades y relaciones se ejemplificará $\mathrm{P}$, pero también siempre que se dé $\mathrm{P}$, se tendrá que presentar una configuración de partes con las propiedades y relaciones en cuestión. Usualmente la relación de superveniencia se toma como una relación de dependencia ontológica asimétrica entre una base de hechos fundantes y los hechos fundados. Como no es un requerimiento conceptual que toda relación de superveniencia sea asimétrica, sin embargo, nada impide que aquí también se califique de este modo la relación entre una propiedad estructural y su base.

El hecho de que una propiedad estructural pueda decirse "superveniente" a la base de propiedades y relaciones instanciadas por las partes del objeto de que se trate, podría parecer extraño. Autores como Lewis no parecen tener ninguna dificultad con relaciones de superveniencia ${ }^{19}$. ¿Por qué estos autores, entonces, critican la inteligibilidad de las propiedades estructurales? La cuestión es que la relación de superveniencia entre dos tipos de hechos describe simplemente cierta covariación entre ellos, pero no especifica porqué se da tal covariación. Puede deberse a que hay identidad entre los hechos de la base y los hechos supervenientes, como también puede deberse a conexiones causales necesarias entre la base y los hechos supervenientes u otras formas de dependencia ontológica. Lo que esperan filósofos como Lewis es una explicación sustantiva de por qué es necesario que, por ejemplo, si las partes de un objeto $\mathrm{x}$ instancian un patrón de propiedades y relaciones determinados, entonces $\mathrm{x}$ instancia

${ }^{19}$ Cf. por ejemplo, Lewis (1999, pp. 8-53), especialmente pp. 33-39; Lewis (1986, pp. 14-17).

Manuscrito - Rev. Int. Fil., Campinas, v. 34, n. 2, pp. 471-521, jul.-dez. 2011. 
la propiedad estructural $\mathrm{P}$ (y al revés), esto es, por qué parece haber una conexión necesaria entre entidades que parecen distintas. Si se quiere, afirmar que hay superveniencia entre las propiedades estructurales y sus bases es simplemente un rótulo a un problema pero no explica cómo es que es inteligible tal cosa.

\section{Críticas a los universales estructurales}

Han existido dos clases de críticas a la postulación de universales estructurales. Una clase de críticas pone en cuestión la inteligibilidad de un universal estructural. Otra clase de críticas rechaza la necesidad de postular tales universales. Se examinarán por orden estas dos formas de crítica.

\subsection{Los universales estructurales no son inteligibles}

David Lewis presenta tres grandes formas en que podría ser comprendido un universal estructural. Como ninguna de esas formas parece aceptable, entonces los universales estructurales no serían realmente entidades inteligibles que podamos incorporar en nuestra ontología ${ }^{20}$. Los universales estructurales podrían ser comprendidos, según Lewis, (i) de acuerdo a una concepción lingüística, (ii) de acuerdo a una concepción pictórica, o (iii) de acuerdo a una concepción mágica. No debe tomarse demasiado en serio la terminología lewisiana en este punto $^{21}$. La concepción lingüística comprende los universales

\footnotetext{
${ }^{20}$ Cf. Lewis (1999), especialmente pp. 87-102.

${ }^{21}$ La terminología adoptada por Lewis aquí es la misma que utiliza para clasificar las diferentes formas de actualismo en metafísica modal, esto es, las diferentes formas en que se conciben los mundos posibles como alguna forma de construcción abstracta (cf. Lewis (1986, pp. 136-191)). Para el caso de los mundos posibles ersatz la terminología tiene más sentido, pues la concepción "lingǘstica" es la que concibe los mundos posibles como conjuntos de oraciones de un lenguaje y la "pictórica" es la que concibe los mundos posibles
}

Manuscrito - Rev. Int. Fil., Campinas, v. 34, n. 2, pp. 471-521, jul.-dez. 2011. 
estructurales como construcciones conjuntistas. La concepción pictórica, por otro lado, comprende los universales estructurales como una forma de composición mereológica. La concepción mágica, por último, es la renuncia a entregar alguna explicación sobre cómo es que un universal se "construye" a partir de otros. Estas opciones no se presentan como exhaustivas, pero si estas formas de entender la naturaleza de un universal estructural no funcionan, entonces es obligación del defensor hallar alguna teoría alternativa que resulte aceptable. Faltando tal teoría alternativa, lo razonable sería suponer que los universales estructurales sencillamente no son inteligibles.

\subsubsection{Construcciones conjuntistas}

En teoría de conjuntos existen una serie de postulados que garantizan conjuntos que pueden ser "construidos" a partir de sus elementos (los que pueden o no ser otros conjuntos). Estas construcciones conjuntistas también permiten especificar relaciones mediante pares ordenados $<\mathrm{a}, \mathrm{b}>=\{\{\mathrm{a}\},\{\mathrm{a}, \mathrm{b}\}\}$. La secuencia de una serie de elementos en un orden específico puede venir dada como un conjunto tal como cualquier otro mediante los mecanismos usuales. La idea aquí es concebir un universal estructural sencillamente como una construcción conjuntista, esto es, como un conjunto especial en el que los elementos básicos son universales y en los que la estructura se va a especificar mediante alguna forma de "codificar" $n$-tuplas ordenadas. Señala Lewis:

como una suerte de "modelo" o "pintura" isomórfica a lo representado. La conexión, en cambio, en el caso de los universales estructurales es tenue, en el mejor de los casos. Lo que ha motivado que Lewis haya seguido la terminología de su discusión en metafísica modal es que su interés en los universales estructurales surge precisamente por la propuesta de Peter Forrest de entender los mundos posibles como universales estructurales (cf. P. Forrest (1986a)).

Manuscrito - Rev. Int. Fil., Campinas, v. 34, n. 2, pp. 471-521, jul.-dez. 2011. 
En la concepción lingüística, un universal estructural es una construcción de teoría de conjuntos a partir de universales simples, tal como una expresión lingüística (interpretada) puede ser tomada como una construcción de teoría de conjuntos a partir de sus palabras. De hecho, pensamos en el universal estructural como en un predicado complejo en un lenguaje en el que las palabras son los universales simples. O, más bien, los universales simples son algunas de las palabras; ellos constituyen el vocabulario no-lógico. También se necesitan palabras lógicas - los conectivos usuales, los cuantificadores y variables- y necesitamos los predicados mereológicos de identidad, inclusión y sobrelapamiento. Estas palabras pueden ser cualquier recurso que ofrezca la construcción de teoría de conjuntos, no importa qué. $^{22}$

Nuestros lenguajes naturales permiten construir oraciones con secuencias de fonemas en un orden específico. Del mismo modo se puede pensar en un universal estructural como una secuencia de universales en un orden específico. Si se necesita "decir" aquí que, por ejemplo, una parte de x instancia tal o cual propiedad o relación, el "ser parte de" puede ser un elemento arbitrario (por ejemplo, $\varnothing$ ó $\{\varnothing\}$ ) que será interpretado de ese modo. Si se necesita "decir" que un objeto x instancia al mismo tiempo dos propiedades $\mathrm{P} y \mathrm{Q}$, la conjunción puede tomarse como un elemento cualquiera que sea interpretado de ese modo. La teoría de conjuntos garantiza la existencia de estructuras de todo tipo, dados ciertos elementos básicos. Aquí los elementos básicos son los universales. Luego, hay todas las estructuras conjuntistas que se quiera a partir de ellos. Se seleccionarán arbitrariamente algunas de esas construcciones conjuntistas y se las tomará como los universales estructurales que interesan.

El problema que Lewis ve en esta estrategia es que requiere de un nivel de elementos básicos desde los que puedan iniciarse las construcciones conjuntistas. Una de las motivaciones fundamentales de la postulación de universales estructurales, sin embargo, es permitir que la realidad pueda poseer una complejidad infinita. Esto es, parte de la

${ }^{22}$ Lewis (1999, p. 87).

Manuscrito - Rev. Int. Fil., Campinas, v. 34, n. 2, pp. 471-521, jul.-dez. 2011. 
motivación para introducir universales estructurales en primer término es hacer comprensible cómo es que pudiese ser que, por ejemplo, ser un átomo de hidrógeno es poseer tales y cuales partes con tales y cuales propiedades y relaciones; que ser un protón es poseer tales y cuales partes con tales y cuales propiedades y relaciones: que ser un quark es poseer tales y cuales partes con tales y cuales propiedades y relaciones, etcétera. No parece haber ningún motivo a priori por el que pueda excluirse que esto vaya a continuar, avanzando siempre hacia estructuras cada vez más pequeñas, sin que lleguemos nunca a un nivel "básico". Podría suceder que todos los universales sean estructurales ${ }^{23}$. Las construcciones conjuntistas, en cambio, exigen un nivel básico de universales que no sean estructurales, esto es, que no sean, a su vez, construcciones conjuntistas ${ }^{24}$.

\subsubsection{Construcciones mereológicas}

Una segunda posibilidad es pensar en los universales estructurales como alguna forma de construcción mereológica ${ }^{25}$. Un universal estructural de metano, por ejemplo, es la propiedad de poseer cinco partes, cuatro de las cuales son átomos de hidrógeno y una de las cuales es un átomo de carbono. Cada uno de los cuatro átomos de hidrógeno tiene una relación de enlace con el átomo de carbono. El universal de ser una molécula de metano es el todo; los universales de ser átomos de hidrógeno y de carbono, así como la relación de "estar enlazado con" son sus partes. La relación que tienen estos universales entre sí es isomórfica a la relación que tienen los átomos respectivos que

${ }^{23}$ Cf. Armstrong (1978, pp. 67-68).

${ }^{24}$ Este requerimiento surge del axioma de fundación en teoría de conjuntos. Este axioma estipula que $(a \neq \varnothing) \rightarrow \exists \mathrm{x}((\mathrm{x} \in a) \wedge((\mathrm{x}$ es un individuo $) \vee((\mathrm{x} \cap$ $a)=\varnothing))$ ). Cf. Potter (2004, pp. 51-53, p. 292). Cf. para la crítica de Lewis (1999, p. 89).

${ }^{25}$ Para los axiomas de mereología estándar, ver nota 11.

Manuscrito - Rev. Int. Fil., Campinas, v. 34, n. 2, pp. 471-521, jul.-dez. 2011. 
conforman moléculas de metano. Como las partes del universal estructural, sin embargo, son universales, pueden encontrarse instanciados en una pluralidad de casos.

En esta concepción un universal estructural es un individuo, no un conjunto. Es mereológicamente compuesto. Los universales más simples que envuelve están presentes en él como sus partes propias. No es nada por sobre y por fuera de ellos, en el sentido de que es nada más que su suma mereológica. Estos universales más simples podrían no ser todavía simples. De hecho podría no haber ningún simple; ahora tenemos una concepción que permite una complejidad infinita ${ }^{26}$.

El problema que existe aquí es que dos sumas mereológicas son idénticas si sus partes son también idénticas. Esto es, las condiciones de identidad de una suma mereológica vienen dadas estrictamente por sus partes. Considérese el caso de una molécula de butano. Esta molécula consta de cuatro átomos de carbono en una fila. Los átomos de carbono de los extremos están enlazados con tres átomos de hidrógeno cada uno y cada uno de los dos átomos de carbono del medio está enlazado a dos átomos de hidrógeno. Una molécula de butano tiene como componentes, entonces, cuatro átomos de carbono, diez átomos de hidrógeno y trece enlaces entre estos átomos. Si las partes de un universal estructural de metano son los universales de ser un átomo de carbono, ser un átomo de hidrógeno y la relación de estar enlazado con algo, entonces el universal estructural de butano tiene exactamente las mismas partes: carbono, hidrógeno y enlace. Serían el mismo universal estructural, cuando obviamente no lo son. Podría decirse aquí que la diferencia entre el metano y el butano es que el primero tiene una instancia de carbono y cuatro instancias de hidrógeno, mientras el segundo tiene cuatro instancias de carbono y diez instancias de hidrógeno. Es obvio, sin embargo, que esta maniobra es fatal. Las instancias de un universal son particulares, no universales, pero se supone que las partes de un universal estructural son universales. De

${ }^{26}$ Lewis (1999, pp. 90-91).

Manuscrito - Rev. Int. Fil., Campinas, v. 34, n. 2, pp. 471-521, jul.-dez. 2011. 
otro modo no se explicaría que el universal estructural fuese instanciable en una pluralidad de casos.

Por lo demás, aún en el caso de que se pudiese introducir algo así como partes "repetibles" en una suma mereológica con lo que distinguir entre tener un átomo de carbono y tener cuatro átomos de carbono, aparece el problema de diferenciar universales estructurales que tienen el mismo número de componentes. Así, por ejemplo, una molécula de isobutano está compuesta, al igual que una molécula de butano, por cuatro átomos de carbono y diez átomos de hidrógeno (más trece enlaces), pero con una estructura diferente. Una molécula de isobutano tiene un átomo de carbono central al que están enlazados tres átomos también de carbono y un átomo de hidrógeno. Cada uno de los átomos de carbono de la "periferia" está, a su vez, enlazado con tres átomos de hidrógeno cada uno. ¿Cómo se diferencia aquí entre la propiedad estructural de ser una molécula de butano y ser una molécula de isobutano? El número de átomos y de enlaces que poseen es la misma. Las partes son las mismas y el número de veces que se "da" cada parte es la misma ${ }^{27}$. No parece haber forma de acomodar la estructura de un universal estructural como algún tipo de construcción mereológica.

¿Qué es lo que sucede, por otro lado, con alguna forma de composición no mereológica? Podrían, en efecto, proponerse ciertas operaciones de composición sui generis que constituyan universales a partir de otros universales. Ésta es, por lo demás, la estrategia que ha seguido la generalidad de los defensores de los universales estructurales.

Mi objeción a esto es que no veo con qué derecho las operaciones son llamadas operaciones de combinación. Una operación se aplica a varios

27 Lewis sugiere otra estrategia que consistiría en la introducción de lo que denomina un "anfibio" que es universal y, al mismo tiempo, puede darse como parte muchas veces. Estos "anfibios" serían tan extraños, sin embargo, que Lewis no considera que siquiera valga la pena explorar cómo es que una teoría de "anfibios" funcionaría (cf. Lewis (1999, pp. 98-100)).

Manuscrito - Rev. Int. Fil., Campinas, v. 34, n. 2, pp. 471-521, jul.-dez. 2011. 
universales; entrega un nuevo universal. Pero si lo que sucede no es mereológico, ¿en qué sentido es lo nuevo compuesto de lo antiguo? ¿En qué sentido no mereológico están presentes en él. Después de todo, ¡no cualquier operación que hace cosas nuevas de viejas es una forma de composición! No hay ningún sentido en que mis padres sean parte de mí y tampoco hay ningún sentido en que dos números sean partes de su máximo común divisor; y dudo de que exista algún sentido en que Bruce sea parte de su conjunto singleton. ${ }^{28}$

Si el defensor de universales estructurales quiere hablar de "parte" en un sentido metafórico, sin ulteriores explicaciones, entonces su concepción es sencillamente una concepción "mágica". Si quiere, sin embargo, ser tomado en serio, requiere explicar cómo es que las "operaciones" que ha postulado permiten "composiciones".

Si insiste que su composición no mereológica es, sin embargo, composición en un sentido perfectamente literal, entonces necesito que se me diga por qué. Decir que lo es no hace que lo sea. ¿Cuál es la noción general de composición de la que la composición mereológica se supone que es sólo un caso especial? ${ }^{29}$

\subsubsection{Magia}

Una tercera alternativa es sostener que un universal estructural ni es un tipo de composición mereológica a partir de los universales que lo “integran”, ni es tampoco un tipo de construcción conjuntista. Aquí, un universal estructural es mereológicamente simple y no es un conjunto (lo que no impide, naturalmente, que pueda ser elemento de un conjunto). Es tal que si algo es una molécula de metano, entonces también hay una instancia de un átomo de carbono. El universal estructural implica necesariamente sus componentes, pero no puede decirse que estos componentes sean sus "partes" más que en sentido metafórico. Lewis protesta que es una invocación a la magia decir que de algún modo- hay una implicación necesaria entre el darse de un

\footnotetext{
${ }^{28}$ Lewis (1999, p. 97).

29 Idem.
}

Manuscrito - Rev. Int. Fil., Campinas, v. 34, n. 2, pp. 471-521, jul.-dez. 2011. 
universal y el darse de otro. Si se trata de entidades diferentes, no puede ser que exista una conexión necesaria entre ellos porque sí. El defensor de los universales estructurales debe explicar cómo es que algo, al instanciarse, hace que se instancia otra cosa. Decir simplemente que "tiene cierto carácter modal" no explica por qué posee tal carácter.

\begin{abstract}
¿Qué sucede con el universal carbono que lo hace estar envuelto en conexiones necesarias con metano? ¿Por qué carbono? ¿Por qué no otro universal, por ejemplo, rubidio? Después de todo, jel universal carbono no tiene más en común con el universal metano que lo que tiene en común con el universal rubidio! Son tres distintos individuos atómicos y eso es. [Esto es, se trata de entidades que no son conjuntos y que no son compuestas mereológicamente.] No hay ninguna razón concebible por la que el universal metano deba, por la necesidad más estricta, arrastrar el universal rubidio adondequiera que vaya. ¿Cómo lo hace, entonces, para arrastrar carbono? 30
\end{abstract}

Faltando aquí una explicación razonable de estas conexiones necesarias, estas deben tenerse por ininteligibles.

\title{
2.2. Los universales estructurales no están justificados
}

Una segunda línea de críticas a la postulación de universales estructurales pone en cuestión que estén justificados. Por supuesto, los filósofos que rechacen de manera general las ontologías de universales, ya sea porque pretendan sustituirlos por clases de tropos o por alguna forma de nominalismo, rechazarán también los universales estructurales. Lo interesante aquí es considerar el caso de filósofos que, aceptando una ontología de universales, no admiten universales estructurales.

En particular, Hugh Mellor sostiene que la forma de saber qué universales son aquellos a los que estamos comprometidos ontológicamente y cómo es que deben distinguirse entre sí es mediante

${ }^{30}$ Lewis (1999, pp. 101-102).

Manuscrito - Rev. Int. Fil., Campinas, v. 34, n. 2, pp. 471-521, jul.-dez. 2011. 
el test de Ramsey ${ }^{31}$. Supóngase que es una ley natural que siempre que algo sea $\mathrm{F}$, entonces estará en relación $\mathrm{R}$ con un objeto que es G. Esto es:

$$
\forall \mathrm{x}(\mathrm{Fx} \rightarrow \exists \mathrm{y}(\mathrm{Gy} \wedge \mathrm{Rxy}))
$$

Supóngase también que es una ley también que todo lo que sea F será también H. Esto es:

$$
\forall \mathrm{x}(\mathrm{Fx} \rightarrow \mathrm{Hx})
$$

Se puede tomar, entonces, la conjunción de todos los enunciados de las leyes en las que aparezca la propiedad F y cuantificar existencialmente la variable que resulta de sustituir ' $F$ ' en todas sus ocurrencias. Suponiendo que (5) y (6) son todas las leyes en las que F aparece ${ }^{32}$, resulta que:

$$
\exists \mathrm{X}[\forall \mathrm{x}(\mathrm{Xx} \rightarrow \exists \mathrm{y}(\mathrm{Gy} \wedge \mathrm{Rxy})) \wedge \forall \mathrm{x}(\mathrm{Xx} \rightarrow \mathrm{Hx})]
$$

Aquí debe entenderse que la cuantificación existencial inicial es objetual y no sustitucional. No se trata de indicar la existencia de algún predicado u otro, sino de indicar la existencia de una propiedad que posee ciertas conexiones nómicas. La propiedad F se fija como la propiedad que exactamente aparece en las conexiones nómicas indicadas por (7). El test de Ramsey es muy semejante al test de Quine de compromiso ontológico con objetos individuales ${ }^{33}$. Supónganse dadas todas las leyes naturales (sean conocidas por nosotros o no, o

\footnotetext{
31 Cf. Ramsey (1968, pp. 199-221).

32 Debe suponerse aquí que (5) y (6) cumplen todos los requisitos adicionales para ser la expresión de una ley natural auténtica. No se presume aquí una visión de las leyes naturales como regularidades.

${ }^{33}$ Cf. Quine (1984, pp. 25-47).
}

Manuscrito - Rev. Int. Fil., Campinas, v. 34, n. 2, pp. 471-521, jul.-dez. 2011. 
sean cognoscibles por nosotros o no). La oración Ramsey $\Sigma$ es la cuantificación existencial de todas las propiedades que han de aparecer en el enunciado de tales leyes naturales. Esas son todas las propiedades que existen.

Muchos filósofos han aceptado que los principios de individuación de una propiedad son las conexiones causales que la posesión de tal propiedad da a sus ejemplificaciones ${ }^{34}$. Mellor sostiene además, sin embargo, que el test de Ramsey implica que no hay universales complejos, lo que obviamente implica que no hay propiedades estructurales que son un tipo de universal complejo, tal como se ha visto. Un universal complejo debería surgir por operaciones de conjunción, disyunción o negación. Si hay un universal complejo $\left[\left(\mathrm{P}_{1} \wedge \mathrm{P}_{2}\right)=\mathrm{P}_{3}\right]$, entonces la oración Ramsey $\Sigma$ cuantificará sobre $\mathrm{P}_{1}$ y $\mathrm{P}_{2}$, pero no es necesario que cuantifique además sobre $\mathrm{P}_{3}$. La propiedad conjuntiva $\mathrm{P}_{3}$ es redundante pues todas las funciones nómicas y causales que debería cumplir, son satisfechas por sus componentes $\mathrm{P}_{1}$ y $\mathrm{P}_{2}$. No hay propiedades conjuntivas, entonces. Lo mismo vale para otras formas de composición ${ }^{35}$.

Podría decirse que hay relaciones causales en las que entra la instanciación de una propiedad conjuntiva, pero en las que no entra la instanciación de cada una de las propiedades componentes por separado. Esto sería un motivo para declarar no redundante a la propiedad conjuntiva. La oración Ramsey $\Sigma$, sin embargo, puede distinguir entre $[\exists \mathrm{X} \exists \mathrm{Y}(\mathrm{X} \ldots \rightarrow \ldots) \wedge(\mathrm{Y} \ldots \rightarrow \ldots)]$, por una parte, $\mathrm{y}$ $[\exists \mathrm{X} \exists \mathrm{Y}((\mathrm{X} \ldots \wedge \mathrm{Y} \ldots) \rightarrow \ldots)]$, por otra ${ }^{36}$. Otro motivo aducido para la introducción de propiedades complejas es permitir que la realidad tenga una estructura infinitamente compleja. Apunta Mellor:

34 Cf. Armstrong (1978, pp. 43-52); Shoemaker (2003, pp. 206-233); Putnam, en $\operatorname{Kim} \&$ Sosa (1999, pp. 243-252).

35 Cf. Mellor (1995, pp. 196-199).

36 ibidem, p. 198.

Manuscrito - Rev. Int. Fil., Campinas, v. 34, n. 2, pp. 471-521, jul.-dez. 2011. 


\begin{abstract}
Pero esta posibilidad no necesita universales complejos, puesto que no hay límite para el número y la complejidad de nuestras leyes ni, por lo tanto, para el número de propiedades sobre las que $\Sigma$ debe cuantificar. Por lo que el alegato de Armstrong, aparte de ser una petición de principio, es un non sequitur. ${ }^{37}$
\end{abstract}

El motivo fundamental, entonces, aducido por Mellor, es que las propiedades complejas -incluyendo las estructurales- son causalmente redundantes, tal como lo pondría de manifiesto la oración Ramsey $\Sigma$. A esto agrega Mellor una razón adicional ${ }^{38}$. Sostiene que no hay truthmakers para verdades negativas, conjuntivas o disyuntivas. Sólo hay trutbmakers para verdades "atómicas". Esto es, si el hecho S es un truthmaker de $\mathrm{p}$, entonces $\neg \mathrm{p}$ es verdadero en caso de que no exista $\mathrm{S}$, sin que sea necesario que exista un hecho que sea el truthmaker de la verdad negativa: un "hecho negativo" o algo semejante. La proposición $[p \wedge q]$ es verdadera si es $p$ es verdadera y $q$ es verdadera. La proposición atómica $\mathrm{p}$ es verdadera, a su vez, si es que existe su truthmaker $\mathrm{S} y$, del mismo modo, q es verdadera si existe su truthmaker respectivo $S^{\prime}$. No es necesario, sin embargo, que exista un truthmaker "conjuntivo" de la proposición [p $\wedge \mathrm{q}$, pues bastan los truthmakers de las proposiciones atómicas. Las propiedades son componentes de hechos, sin embargo. Si hubiese una propiedad negativa $[\neg \mathrm{P}]$, entonces la instanciación de esa propiedad por un objeto constituiría un hecho atómico y requeriría un truthmaker. Del mismo modo, si hubiese una propiedad conjuntiva $\left[\mathrm{P}_{1} \wedge \mathrm{P}_{2}\right]$, entonces la instanciación de esa propiedad por un objeto sería un hecho atómico que requeriría un truthmaker especial, contra la hipótesis. Por lo tanto, si no hay truthmakers de proposiciones complejas, entonces no hay propiedades complejas.

Las críticas de Mellor, sin embargo, pueden ser respondidas de manera relativamente rápida. En primer lugar, hay una diferencia

\footnotetext{
37 Mellor (1995, p. 198).

38 ibidem, pp. 198-199.
}

Manuscrito - Rev. Int. Fil., Campinas, v. 34, n. 2, pp. 471-521, jul.-dez. 2011. 
importante entre la existencia de infinitas propiedades simples y la inexistencia de propiedades simples. No hay ninguna duda de que una oración Ramsey podría -formulada en un lenguaje infinitario apropiado- hacer espacio para lo primero, pero no para lo segundo, si es que no se cuantifica directamente sobre las propiedades complejas, incluyendo las estructurales. Aún aceptando con Mellor que la forma de determinar qué propiedades realmente existen es mediante el test de Ramsey, esto no lleva a desechar las propiedades complejas. Sería muy extraño, por lo demás, pretender sostener que la realidad no puede tener una complejidad infinita debido a que una oración Ramsey que incluya sólo propiedades simples no podría expresar esa complejidad. En segundo lugar, supóngase que hay realmente ciertas propiedades simples que componen todas las restantes. El hecho de que tales propiedades sean las que releva la oración Ramsey no debe verse como un motivo para pensar que no existen las propiedades complejas y estructurales "construidas" mediante ellas. Todo lo que se afirma cuando se afirma que hay una instancia de una propiedad estructural, tal como se ha visto, es que ciertos objetos que conforman una suma mereológica tienen determinada naturaleza intrínseca y se encuentran entre sí en ciertas relaciones. Si el defensor del test de Ramsey acepta esto, entonces acepta que hay propiedades estructurales ${ }^{39}$. En tercer lugar, si la existencia de propiedades complejas obliga a postular truthmakers que no parecen estados de cosas o hechos atómicos, entonces pueden concluirse perfectamente que deben existir tales hechos no atómicos. Si hay motivos sistemáticos generales que hacen razonable aceptar universales complejos y estructurales, entonces esos motivos pueden inclinar la lectura de este condicional como un modus ponens y no como un modus tollens.

39 Una línea de argumentación semejante desarrollada para la defensa de objetos ordinarios puede encontrarse en Thomasson (2007, pp. 9-53).

Manuscrito - Rev. Int. Fil., Campinas, v. 34, n. 2, pp. 471-521, jul.-dez. 2011. 
En lo que sigue, entonces, no se continuará la discusión de las críticas de Mellor. Se concentrará la atención en las críticas de ininteligibilidad de David Lewis.

\section{Defensa de los universales estructurales}

Se han presentado una serie de defensas de los universales estructurales frente a las críticas ${ }^{40}$. En términos generales, se ha sostenido que: (i) no deben restringirse las formas de composición a la mereología (estándar) y a la teoría de conjuntos (estándar); y (ii) pueden postularse formas de composición de propiedades mediante "tipos de estados de cosas", "relaciones formales" o propiedades de orden superior.

Antes de pasar a discutir estos alegatos será conveniente hacer notar que en las teorías formales de propiedades se presentan una serie de "operaciones" que, aplicadas a propiedades, arrojan otras propiedades que, de alguna manera, están "compuestas" de las propiedades más básicas. Por ejemplo, Chris Swoyer, describe un conjunto de familias de operaciones sobre propiedades y relaciones ${ }^{41}$. Cada propiedad posee una $n$-adicidad determinada y una extensión constituida por el conjunto de objetos que la ejemplifican.

(A) Negación: $\mathbf{N e g}(\mathrm{P})$ es la negación de P. Si P es una relación $n$-ádica, entonces $\mathbf{N e g}(\mathrm{P})$ es también $n$-ádica. La extensión de $\mathbf{N e g}(\mathrm{P})$ es el conjunto de todos los individuos que no caen bajo P.

40 Cf. Forrest (1986a, 1986b); Armstrong (1986); Armstrong (1997, pp. 31-38); Bigelow \& Pargetter (1989); Bigelow \& Pargetter (1990, pp. 82-92); Pagès (2002).

${ }^{41}$ Cf. Swoyer (1998). La descripción de las operaciones en pp. 302-303. Forrest presenta tres operaciones para la conformación de universales estructurales, dos de las cuales son equivalentes a las operaciones de conjunción y de reflexión (las denomina, respectivamente, producto y contracción). A estas dos operaciones añade una tercera de proyección de la que se tratará luego (cf. Forrest (1986a, pp. 17-19)).

Manuscrito - Rev. Int. Fil., Campinas, v. 34, n. 2, pp. 471-521, jul.-dez. 2011. 
(B) Conjunción: $\operatorname{Conj}(\mathrm{P}, \mathrm{Q})$. Si P es $n$-ádica y Q es $m$-ádica, entonces $\operatorname{Conj}(\mathrm{P}, \mathrm{Q})$ es $(n+m)$-ádica. Nótese la diferencia con la operación booleana de "conjunción" indicada arriba. Esta última sólo puede darse entre propiedades con la misma adicidad, pues se trata de que el mismo objeto o la misma $n$-tupla de objetos instancie P y Q.

(C) Universalización: Univi $(\mathrm{P})$ es la cuantificación universal del $i$-avo lugar $(1 \leq i \leq n)$ de las variables de la propiedad P. Esta es, entonces, una familia de operaciones de universalización, existiendo una diferente para cada lugar de las variables de una relación. Si P es $n$-ádica, entonces $\operatorname{Univ} i(\mathrm{P})$ es $(n-1)$-ádica.

(D) Conversión: Convij(P) es la conversión de los lugares $i$ y $j$ entre las variables de una relación. Se trata de una familia de operaciones, una para cada uno de los pares de variables de una relación. Si P es $n$-ádica, entonces $\mathbf{C o n v}_{i j}(\mathrm{P})$ es también $n$-ádica.

(E) Reflexión: $\boldsymbol{R e f}_{i j}(\mathrm{P})$ es la identificación de los lugares $i$ y $j$ entre las variables de una relación. Se trata, nuevamente, de una familia de operaciones, una para cada par ordenado de variables de una relación. Si P es $n$-ádica, entonces $\boldsymbol{R e f}_{i j}(\mathrm{P})$ es $(n-1)$-ádica.

(F) Inserción (plugging): Plugi(P, Juan) es la inserción de Juan en el $i$-avo lugar de las variables de la relación P. Es una familia de operaciones también. Si P es una relación $n$-ádica, entonces $\operatorname{Plug}_{i}(\mathrm{P}, \mathrm{Juan})$ es una relación (n-1)-ádica. Nótese que con esta operación se pueden tratar las proposiciones como propiedades 0-ádicas. En efecto, sea la propiedad monádica $[\lambda x$ (x es un gato) $]$. Plug $1([\lambda x$ (x es un gato) $]$, Micifuz) es la 
propiedad [Micifuz es un gato]. Esto es, simplemente, una proposición ${ }^{42}$.

¿Cómo vendría dado un universal estructural mediante estas operaciones? Considérese el caso de la propiedad de ser una molécula de metano. Tal como se ha visto, en una molécula de metano están implicados un átomo de carbono, cuatro átomos de hidrógeno y cuatro relaciones de enlace. Sean $\mathrm{C}$ la propiedad monádica de ser carbono, $\mathrm{H}$ la propiedad monádica de ser hidrógeno y $\mathrm{E}$ la relación diádica de enlace. Tómese, en primer lugar, la conjunción de todas estas propiedades con el número de instancias requeridas. Esto es:

$$
\operatorname{Conj}\left(\mathrm{Cx}_{1}, \mathrm{Hx}_{2}, \mathrm{Hx}_{3}, \mathrm{Hx}_{4}, \mathrm{Hx}_{5}, \mathrm{Ex}_{6} \mathrm{x}_{7}, \mathrm{Ex}_{8} \mathrm{x}_{9}, \mathrm{Ex}_{10} \mathrm{x}_{11}, \mathrm{Ex}_{12} \mathrm{x}_{13}\right)
$$

Esta es una relación 13-ádica que surge por la operación reiterada de la conjunción diádica, de este modo:

$$
\begin{aligned}
& \operatorname{Conj}\left(\operatorname { C o n j } \left(\operatorname { C o n j } \left(\operatorname { C o n j } \left(\operatorname { C o n j } \left(\operatorname { C o n j } \left(\operatorname{Conj}\left(\operatorname{Conj}\left(\mathrm{Cx}_{1}, \mathrm{Hx}_{2}\right), \mathrm{Hx}_{3}\right)\right.\right.\right.\right.\right.\right. \text {, } \\
& \left.\left.\left.\left.\left.\left.\mathrm{Hx}_{4}\right), \mathrm{Hx}_{5}\right), \mathrm{Ex}_{6} \mathrm{x}_{7}\right), \mathrm{Ex}_{8} \mathrm{x}_{9}\right), \operatorname{Ex}_{10} \mathrm{x}_{11}\right), \operatorname{Ex}_{12} \mathrm{x}_{13}\right)
\end{aligned}
$$

Ahora debe aplicarse reiteradamente la operación de reflexión para fusionar diferentes variables de esta relación 13-ádica y obtener la propiedad estructural que interesa. Así:

$$
\begin{aligned}
& \operatorname{Ref}_{1-6}\left(\operatorname { R e f } _ { 2 - 7 } \left(\operatorname { R e f } _ { 1 - 8 } \left(\operatorname { R e f } _ { 3 - 9 } \left(\operatorname { R e f } _ { 1 - 1 0 } \left(\operatorname { R e f } _ { 4 - 1 1 } \left(\operatorname { R e f } _ { 1 - 1 2 } \left(\operatorname{Ref}_{5-}\right.\right.\right.\right.\right.\right.\right. \\
& { }_{13}\left(\operatorname { C o n j } \left(\mathrm{Cx}_{1}, \mathrm{Hx}_{2}, \mathrm{Hx}_{3}, \mathrm{Hx}_{4}, \mathrm{Hx}_{5}, \mathrm{Ex}_{6} \mathrm{x}_{7}, \mathrm{Ex}_{8} \mathrm{x}_{9}, \mathrm{Ex}_{10} \mathrm{x}_{11}\right.\right. \text {, } \\
& \left.\left.\left.\left.\left.\left.\left.\left(\mathrm{Ex}_{12} \mathrm{x}_{13}\right)\right)\right)\right)\right)\right)\right)\right) \text { ) }
\end{aligned}
$$

\footnotetext{
42 Swoyer limita las operaciones de universalización y de inserción a relaciones diádicas, pero la extensión a propiedades monádicas indicada aquí está prevista (cf. Swoyer (1998, p. 303)).

Manuscrito - Rev. Int. Fil., Campinas, v. 34, n. 2, pp. 471-521, jul.-dez. 2011.
} 
De lo que resulta la propiedad compleja que puede expresarse con el siguiente predicado:

(11) $\lambda \mathrm{x}_{1} \lambda \mathrm{x}_{2} \lambda \mathrm{x}_{3} \lambda \mathrm{x}_{4} \lambda \mathrm{x}_{5}\left[\mathrm{Cx}_{1} \wedge \mathrm{Hx}_{2} \wedge \mathrm{Hx}_{3} \wedge \mathrm{Hx}_{4} \wedge \mathrm{Hx}_{5} \wedge \mathrm{Ex}_{1} \mathrm{x}_{2} \wedge\right.$ $\left.\operatorname{Ex}_{1} x_{3} \wedge \operatorname{Ex}_{1} x_{4} \wedge \operatorname{Ex}_{1} x_{5}\right]$

Lo que se expresa en (11) es una relación 5-ádica que se instancia entre cinco objetos siempre que estos sean un átomo de carbono, cuatro átomos de hidrógeno y existan relaciones diádicas de enlace entre estos átomos según se especifica. Es necesario aquí, sin embargo, hacer una precisión importante. Una propiedad estructural es una propiedad que se atribuye a un objeto dada la configuración de sus partes. La propiedad (11) es una relación compleja entre cinco objetos, pero no es una propiedad que sea atribuida a un objeto que posee cinco partes que satisfacen (11). Una propiedad estructural, entonces, requiere de manera complementaria la estipulación que las entidades en cuestión que han de entrar en la relación compleja han de ser todas ellas partes de una única suma mereológica que, a su vez, habrá de ser la entidad a la que la propiedad estructural es inmediatamente atribuida. Forrest, por esto, introduce una operación adicional denominada por él como "proyección":

(G) Proyección: Proj(P) es la propiedad que posee la suma de $x_{1}, x_{2}, \ldots$, $\mathrm{x}_{\mathrm{n}}$ que caen bajo la propiedad $n$-ádica P. Esto es, siempre que una $n$ tupla de objetos instancia cierta relación $\mathrm{P}$, la suma mereológica de tales objetos instanciará un universal Proj(P). Cualquiera sea el número de variables que tenga $\mathrm{P}$, como la suma de los objetos que la instancian es única, Proj( $(\mathrm{P})$ será siempre monádica.

Tal como se ha indicado, muchos filósofos aceptan el principio de sumas mereológicas irrestrictas, por lo que siempre que, por ejemplo, cinco objetos instancien (11) existirá la suma mereológica de tales cinco objetos que podrá decirse instanciando una propiedad monádica Manuscrito - Rev. Int. Fil., Campinas, v. 34, n. 2, pp. 471-521, jul.-dez. 2011. 
peculiar: ser tal que se poseen cinco partes que instancian la relación (11). Como no todos aceptan las sumas mereológicas irrestrictas, conviene, sin embargo, introducir este requerimiento mereológico de manera expresa. Esto puede hacerse sin grandes dificultades suponiendo que hay una relación de ser algo parte propia de algo $[\lambda x \lambda y$ $(\mathrm{x}<\mathrm{y})$ ]. La propiedad estructural de ser una molécula de metano quedaría entonces tal como lo expresa este predicado:

$$
\begin{aligned}
& \lambda \mathrm{y} \exists \mathrm{x}_{1} \exists \mathrm{x}_{2} \exists \mathrm{x}_{3} \exists \mathrm{x}_{4} \exists \mathrm{x}_{5}\left[\left(\mathrm{x}_{1}<\mathrm{y}\right) \wedge\left(\mathrm{x}_{2}<\mathrm{y}\right) \wedge\left(\mathrm{x}_{3}<\mathrm{y}\right) \wedge\left(\mathrm{x}_{4}<\mathrm{y}\right) \wedge\right. \\
& \left(\mathrm{x}_{5}<\mathrm{y}\right) \wedge \mathrm{Cx}_{1} \wedge \mathrm{Hx}_{2} \wedge \mathrm{Hx}_{3} \wedge \mathrm{Hx}_{4} \wedge \mathrm{Hx}_{5} \wedge \mathrm{Ex}_{1} \mathrm{x}_{2} \wedge \mathrm{Ex}_{1} \mathrm{x}_{3} \wedge \\
& \left.\mathrm{Ex}_{1} \mathrm{x}_{4} \wedge \mathrm{Ex}_{1} \mathrm{x}_{5}\right]
\end{aligned}
$$

De manera general, entonces, puede decirse que una propiedad estructural es la propiedad de tener partes propias con cierta naturaleza intrínseca $\mathrm{N}$ y con relaciones externas entre sí $\mathrm{R}$ :

$$
\begin{aligned}
& \lambda \mathrm{y} \exists \mathrm{x}_{1} \exists \mathrm{x}_{2} \ldots \exists \mathrm{x}_{\mathrm{n}}\left[\left(\mathrm{x}_{1}<\mathrm{y}\right) \wedge\left(\mathrm{x}_{2}<\mathrm{y}\right) \wedge \ldots \wedge\left(\mathrm{x}_{\mathrm{n}}<\mathrm{y}\right) \wedge \mathrm{N}_{1} \mathrm{x}_{1} \wedge\right. \\
& \left.\mathrm{N}_{2} \mathrm{x}_{2} \wedge \ldots \wedge \mathrm{N}_{\mathrm{n}} \mathrm{x}_{\mathrm{n}} \wedge \operatorname{Rx}_{1} \mathrm{x}_{2} \ldots \mathrm{x}_{\mathrm{n}}\right]
\end{aligned}
$$

Por lo demás, el paso de (11) a (12) no requiere introducir más operaciones que las presentadas por Swoyer, pues puede obtenerse mediante aplicaciones iteradas de la conjunción, la reflexión, la negación y la universalización, aunque esto es algo que no se desarrollará aquí ${ }^{43}$.

Estas operaciones, entonces, permiten "construir" universales a partir de universales. ¿Qué es lo que son tales operaciones, sin

\footnotetext{
${ }^{43}$ De manera esquemática el procedimiento es el siguiente: a la relación 5-ádica (11) se añaden por conjunción todas las instanciaciones de $\left[\mathrm{x}_{\mathrm{i}}<\mathrm{y}\right]$ que se requieran. Luego, se ajustan las variables mediante reflexión. Para introducir las cuantificaciones existenciales, por último, se explota el hecho de que $[\exists \mathrm{x} F \mathrm{Fx}$ $\neg \forall \mathrm{x} \neg \mathrm{Fx}]$, negando la relación completa, universalizando y luego volviendo a negar todas las veces que sea necesario.
}

Manuscrito - Rev. Int. Fil., Campinas, v. 34, n. 2, pp. 471-521, jul.-dez. 2011. 
embargo? ¿No podrían estas apaciguar los pruritos de Lewis? ¿No podrían considerarse suficientemente inteligibles por sí mismas? Por supuesto, un tipo de respuesta legítima para las críticas de Lewis sería simplemente rechazar que las únicas formas inteligibles de composición sean la conjuntista y la mereológica ${ }^{44}$ añadiendo estas operaciones como una forma de composición sui generis. Las propiedades estructurales ni son conjuntos, ni son sumas mereológicas, y si uno asume de entrada que esas son todas las maneras en que algo puede estar compuesto de otra cosa, entonces -obviamente- habrá que rechazar las propiedades estructurales y, con ellas, las operaciones indicadas, así como también los estados de cosas. Esto es, si (i) toda composición o es mereológica o es conjuntista, y (ii) los universales estructurales ni son sumas mereológicas ni son construcciones conjuntistas, entonces los universales estructurales no son inteligibles. Este mismo condicional puede ser utilizado por el defensor de los universales estructurales, sin embargo, para un modus tollens. Esto es, dado que claramente comprendemos qué es un universal estructural (por ejemplo, mediante las operaciones indicadas) y claramente los universales estructurales ni son sumas mereológicas ni son construcciones conjuntistas, entonces no toda forma de composición es, o bien mereológica, o bien conjuntista. Todo depende aquí de qué es lo que se estime "inteligible" de entrada o, si se quiere, "más inteligible" de entrada.

Esto debe unirse, además, al hecho de que Lewis intencionadamente se remite sólo a teoría de conjuntos estándar y a mereología estándar. Una y otra son teorías formales que se definen por sus axiomas (junto con la lógica subyacente que garantiza los teoremas que puedan ser deducidos a partir de tales axiomas). Hay, sin embargo, teorías de conjuntos no estándar en las que, por ejemplo, no hay axioma de fundación. En teorías como estas nada impediría la

44 Este tipo de estrategia es la que adoptan Armstrong y Forrest; cf. Armstrong (1986); Forrest (1986b).

Manuscrito - Rev. Int. Fil., Campinas, v. 34, n. 2, pp. 471-521, jul.-dez. 2011. 
existencia de estructuras de infinita complejidad. Se trata, por lo demás, de teorías perfectamente consistentes. ¿Por qué no puede apelarse a estas teorías en vez de las estándar? ¿Es que ZF está inscrita en los cielos como la verdad última de lo que hay?

Es obvio, sin embargo, que estas estrategias deben reservarse como último recurso. En principio, debe tratar de darse una explicación lo más precisa posible de cómo es que un universal podría construirse a partir de otro. Las críticas de Lewis deben verse como un desafío que los defensores de los universales estructurales deben enfrentar, más que una refutación en regla. Hay dos teorías bien conocidas que especifican cómo es que algo se "compone" de otras cosas: la teoría de conjuntos axiomatizada estándar y la mereología estándar. La teoría de conjuntos, en particular, surge de un complicado desarrollo en el que nociones que parecían perfectamente bien comprendidas resultaron ser finalmente inconsistentes. Fue un arduo trabajo lidiando contra los abismos de la inconsistencia lo que condujo a las formulaciones axiomáticas actualmente aceptadas. No deberían tratarse con liviandad, por lo tanto. Es muy sencillo, en efecto, hacer apelación a cierta "composición" sui generis, pero esa actitud desaprensiva ya ha conducido al desastre antes. Una precaución teórica mínima exige que en este caso se preste una atención detenida a un espécimen de composición que parece escapar de los registros conocidos.

Esto es, aún cuando se estime que las operaciones descritas arriba son perfectamente inteligibles por sí mismas y que, por lo tanto, los universales estructurales son también perfectamente inteligibles (lo que implica eo ipso que no toda forma de composición es o conjuntista o mereológica), debe hacerse el intento de precisar del mejor modo qué tipo de estructura es la que posee un universal estructural para aliviar las sospechas de autores como Lewis. Es patente que no se puede hacer aparecer a los universales estructurales como conjuntos (estándar) o sumas mereológicas (estándar). Debe buscarse la naturaleza de tales estructuras en otro sitio. En lo que sigue se presentarán, primero, ciertas formas de explicar la estructura de los universales estructurales 
que no parecen apropiadas, para luego defender la teoría que parece más adecuada, tanto desde un punto de vista de parsimonia explicativa, como desde la perspectiva de una ontología general.

\subsection{Operaciones}

Convendrá considerar en primer término qué puede tomarse como una "operación". Se han presentado siete operaciones arriba y se ha mostrado que con ellas se tiene todo lo que parece requerirse para generar universales estructurales a partir de otros universales más básicos. Podría uno pensar que se trata de entidades matemáticas como cualquier otra entidad matemática y que esto es suficiente como explicación. En general, una “operación” en matemáticas es una función que, dados ciertos argumentos, arroja un determinado "resultado". Tal como todas las funciones, es característico de las operaciones que el "resultado" sea único. Una función, por otro lado, se toma ordinariamente como un tipo de relación y una relación es un conjunto de $n$-tuplas ordenadas. Tal como se ha visto, una $n$-tupla ordenada es un conjunto con una cierta estructura particular. Tomadas tal como aparece a primera vista, entonces, las operaciones serían conjuntos. Conjuntos con cierta complejidad especial, pero conjuntos al fin, en los que los elementos básicos serían universales.

El problema aquí es que si se trata de conjuntos con una estructura especial constituidos por universales, entonces se requiere un nivel de universales básicos, tal como lo ha puesto de relieve Lewis. Se pretende, sin embargo, permitir que existan estructuras infinitamente complejas y, en particular, permitir que todos los universales sean estructurales. No parecen servir las operaciones, por lo tanto, al menos tomadas como entidades matemáticas "tal como cualquier otra".

Si las operaciones han de ser concebidas como otro tipo de entidad no conjuntista, por otro lado, entonces será necesario entregar una explicación satisfactoria sobre qué entidades son. 


\subsection{Tipos de estados de cosas}

Armstrong ha propuesto considerar a los universales estructurales como tipos de estados de cosas ${ }^{45}$. En general, para Armstrong, los universales se encuentran siempre instanciados en algún individuo. No son nada "por encima" o "por fuera" de los particulares que los instancian. La instanciación de un universal por un particular es un estado de cosas. Como el universal es también, en virtud de su naturaleza, esencialmente repetible, puede ser concebido como un tipo general de estado de cosas, "abstracto", si se quiere, de sus ejemplificaciones particulares ${ }^{46}$. Un universal estructural es, entonces, un tipo de estados de cosas complejo. Si se trata, por ejemplo, del universal de ser una molécula de agua, entonces el universal estructural es el tipo general de estado de cosas de ser algo una molécula de agua consistente en que hay un átomo de oxígeno, dos átomos de hidrógeno y los átomos de hidrógeno están cada uno de ellos enlazados con el átomo de oxígeno.

Esto parece correcto. No parecen haber dificultades para aceptar que los universales estructurales son tipos de estados de cosas ${ }^{47}$. El problema es que no se ve cómo es que esto podría aquietar las dudas de críticos como Lewis. Es obvio, en efecto, que la instanciación de un universal estructural -si existe tal cosa-implica la instanciación de otros universales. Es obvio, por lo tanto, que la instanciación de un universal estructural implica la existencia de un estado de cosas "complejo". El problema es que lo que se pretende aquí es que se explique cómo es que se arroja tal resultado, esto es, cómo es que se generan estados de cosas "complejos" cuando se instancian universales estructurales. Decir

\footnotetext{
${ }^{45}$ Cf. Armstrong (1997, pp. 31-38), especialmente p. 33.

46 Una explicación general de este punto puede encontrarse en Armstrong (1997, pp. 28-31).

${ }^{47}$ Salvo, naturalmente, las dudas que pudiesen plantearse sobre la existencia de universales no instanciados.
}

Manuscrito - Rev. Int. Fil., Campinas, v. 34, n. 2, pp. 471-521, jul.-dez. 2011. 
que se trata de un tipo de estado de cosas "complejo" no hace sino reiterar lo que ya sabemos desde el principio. No es explicación.

\subsection{Relaciones formales}

Pagès ha presentado una explicación de los universales estructurales como "relaciones formales" entre objetos ${ }^{48}$, esto es, se trataría de relaciones que se dan en objetos porque es verdadero afirmar de tales objetos cierta fórmula. Correctamente indica Pagès que cuando se instancia un universal estructural de ser una molécula de metano es aplicable un predicado como el predicado (11) arriba, esto es:

(11) $\lambda \mathrm{x}_{1} \lambda \mathrm{x}_{2} \lambda \mathrm{x}_{3} \lambda \mathrm{x}_{4} \lambda \mathrm{x}_{5}\left[\mathrm{Cx}_{1} \wedge \mathrm{Hx}_{2} \wedge \mathrm{Hx}_{3} \wedge \mathrm{Hx}_{4} \wedge \mathrm{Hx}_{5} \wedge \mathrm{Ex}_{1} \mathrm{x}_{2} \wedge\right.$ $\left.\operatorname{Ex}_{1} x_{3} \wedge \operatorname{Ex}_{1} x_{4} \wedge \operatorname{Ex}_{1} x_{5}\right]$

Puede decirse que una 5-tupla de objetos de los que es verdadero sostener (11) son tales que se encuentran en determinada relación. Mediante las modificaciones apropiadas pueden generarse predicados formales para las propiedades de constituir una molécula de butano o una molécula de isobutano ${ }^{49}$. Es indispensable añadir a esta explicación las relaciones mereológicas que deben darse entre los objetos que se encuentran en la relación especificada. Una propiedad estructural, en efecto, es una propiedad estructural monádica que se instancia en un objeto que es la suma mereológica de ciertas partes entre las cuales se instancia determinada relación. Es muy fácil, sin embargo, suplementar

48 Cf. Pagès (2002). Señala Pagès: "Mi solución al problema provee una respuesta a esta cuestión [la cuestión sobre cómo se compone un universal mediante otros]: construyendo universales estructurales mediante relaciones formales seleccionadas por fórmulas abiertas como (1) y (2)" (219) [(1) y (2) son fórmulas análogas a (11) arriba, pero sin ligar las variables libres mediante operadores lambda].

49 Pagès desarrolla las fórmulas en cuestión en Pagès (2002, pp. 219-220, nota 5).

Manuscrito - Rev. Int. Fil., Campinas, v. 34, n. 2, pp. 471-521, jul.-dez. 2011. 
la teoría con una formulación como (13) arriba que subsana esta cuestión, por lo que esto no es un problema grave.

La teoría de Pagès parece claramente más cercana al objetivo que las anteriores. Hay algunas dificultades más serias, sin embargo, que será necesario tomar en consideración para una explicación exitosa. En primer lugar, es especialmente perturbador el que se haga depender los universales estructurales de fórmulas que ha de darse en algún lenguaje. Qué lenguajes existan y qué capacidades expresivas tenga un lenguaje dado es una cuestión contingente. Un lenguaje natural cualquiera tiene un repertorio limitado de capacidades expresivas que no tiene porqué corresponder a los universales realmente existentes. Esto es, parece razonable suponer que no necesariamente tendremos nombres para cada universal existente. Como los universales estructurales dependen de la existencia de fórmulas en algún lenguaje en la concepción de Pagès, todos los universales estructurales que dependan de universales innominados deberán declararse inexistentes. Si súbitamente se incorporan más recursos expresivos en un lenguaje, entonces súbitamente se "crearán" universales que antes no existían y si un lenguaje súbitamente perdiera recursos expresivos, "desaparecerían" universales que antes existían. Esto parece una restricción inaceptable.

Podría intentarse aquí suplementar los recursos expresivos para construir fórmulas mediante un lenguaje "lagadoniano". Un lenguaje lagadoniano es un lenguaje con capacidad expresiva máxima en el que todo es nombre de sí mismo ${ }^{50}$. Entonces, cada propiedad sería un nombre de sí mismo y podría entrar -como término- en las fórmulas que especifican relaciones formales. Es obvio, sin embargo, que un "lenguaje" semejante no sería ni aprendible ni utilizable por seres racionales como nosotros, por lo que difícilmente merezca el

${ }^{50}$ La hipótesis de un lenguaje lagadoniano fue introducida por David Lewis para suplementar los recursos expresivos de las teorías modales lingüísticas que conciben los mundos posibles como conjuntos máximamente consistentes de oraciones (cf. Lewis (1986, pp. 144-150)).

Manuscrito - Rev. Int. Fil., Campinas, v. 34, n. 2, pp. 471-521, jul.-dez. 2011. 
calificativo de "lenguaje". Suponer un lenguaje utópico de este tipo para entregar todas las fórmulas requeridas es, realmente, un índice de que los universales no dependen de ningún lenguaje. Podría también pensarse que, aún cuando no existan términos para referirse directamente a todos los universales, podrían estos ser dados descriptivamente mediante, por ejemplo, oraciones Ramsey apropiadas. El problema es que una oración Ramsey funciona para fijar cierta propiedad si es que hay relaciones nómicas conocidas de la propiedad desconocida y no-nombrada con propiedades conocidas y nombradas. Pero una propiedad desconocida y no-nombrada puede estar en relaciones nómicas con otras relaciones que también son desconocidas y no-nombradas. Para éstas no hay oraciones Ramsey.

Hay, sin embargo, un punto más fundamental. Aún suponiendo que los problemas relativos a las capacidades expresivas pudiese ser reparado, parece simplemente errado suponer que la cuestión ontológica sobre qué universales hay dependa de qué fórmulas pueden o no ser atribuidas con verdad a un objeto o a una $n$-tupla de objetos (y dependa de qué fórmulas puedan o no ser construidas en un lenguaje). La relación de dependencia parece ser exactamente la inversa. Si hay fórmulas que puedan ser atribuidas con verdad a un objeto o una n-tupla de objetos, ello se funda en el hecho de que ese objeto u objetos poseen tales o cuales propiedades y relaciones, y no al revés. Qué propiedades y relaciones existan no es una cuestión que pueda decidirse a priori. No hay una correlación uno-a-uno entre predicados y propiedades, porque no toda propiedad tendrá asociada un predicado y porque no todo predicado debe verse como refiriendo a una propiedad. $\mathrm{Si}$ hay propiedades estructurales, este hecho no puede ser ontológicamente dependiente de que sea verdadero atribuir fórmulas de algún lenguaje a $n$-tuplas de objetos ${ }^{51}$. Los universales estructurales ni

51 Este es un aspecto central de la concepción de universales "escasos" defendida de manera paradigmática por Armstrong. Cf. (1978, pp. 7-18; 1989, pp. 84-88; 1997, pp. 25-28).

Manuscrito - Rev. Int. Fil., Campinas, v. 34, n. 2, pp. 471-521, jul.-dez. 2011. 
son relaciones formales ni dependen de la existencia de relaciones formales.

\subsection{Universales de orden superior}

Los universales estructurales son universales y no otra cosa. Esto debe hacernos desconfiar de estrategias que intentan explicarlos por entidades de naturaleza muy diferente, como fórmulas de algún lenguaje, construcciones conjuntistas o mereológicas. La concepción que se pretende adelantar aquí se encuentra en la línea de lo planteado por John Bigelow y Robert Pargetter, aunque con bastantes modificaciones ${ }^{52}$. En esta concepción los universales estructurales son complexiones de universales con otros universales. No se requiere apelar a conjuntos o sumas para explicar cómo es que estos universales resultan combinados, pues universales de orden superior permiten realizar esta tarea teórica.

Bigelow y Pargetter consideran el caso de los universales estructurales por analogía con otros casos en los que están envueltos diferentes niveles de universales. Es obvio, por de pronto, que hay universales de diferentes niveles, esto es, universales que se instancian en individuos, pero también hay universales que se instancian dado que se instancian otros universales y universales que se instancian dado que se instancian otros universales que se instancian, a su vez, dado que se instancian otros universales. Etcétera. Propiedades que se estiman muy sencillas presentan una estructura bastante compleja de universales de diferente orden. Considérese la propiedad de medir exactamente 2 centímetros de longitud. Se trata de una propiedad "determinada", según se ha explicado. El hecho de que un objeto, sea $b$, instancia esta propiedad implica que $b$ instancia también la propiedad de tener una longitud (la propiedad "determinable" correlativa con la propiedad

\footnotetext{
52 Cf. Bigelow \& Pargetter (1989, pp. 82-92). Se tomará el segundo texto de manera preferente por encontrarse ahí una presentación más articulada.
}

Manuscrito - Rev. Int. Fil., Campinas, v. 34, n. 2, pp. 471-521, jul.-dez. 2011. 
determinada respectiva), pero no sólo eso. Cuando se le atribuye al objeto $b$ la propiedad de tener 2 centímetros de longitud se establecen relaciones de "tener mayor longitud que" y "tener menor longitud que" con todos los restantes objetos que tienen la propiedad determinable de tener una longitud y, lo que es más, con todas las posibles instanciaciones de la propiedad determinable de tener una longitud. Es propio de una propiedad como tener una longitud de 2 centímetros el que su posesión implica un plexo de relaciones con todas las restantes propiedades determinadas de tener longitud. Nótese, en particular, que estas relaciones han de indicar con precisión cuán diferente es la longitud de dos objetos ${ }^{53}$. Lo que se indica aquí para la longitud vale para cualquier otra magnitud física. ¿Cómo se explican estas implicaciones entre diferentes universales? Puede verse que también aquí un lewisiano podría manifestar dudas sobre la inteligibilidad de estas relaciones entre "entidades diferentes". Si hay una respuesta satisfactoria aquí, también hay esperanzas de que pueda haberla para el caso de universales estructurales.

Bigelow y Pargetter ofrecen una explicación de esta compleja trama de relaciones de implicación entre universales ${ }^{54}$. No es necesario hacer aquí una discusión pormenorizada de la solución que ofrecen, pero indicará el estilo de teoría que podrá ser aplicada para el caso de los universales estructurales. En primer término, una propiedad determinable ha de tomarse como una propiedad de segundo nivel. Esto es, no se trata de una propiedad instanciada por un individuo, sino que se trata de la propiedad de instanciar una propiedad determinada. Esto explica porqué si algo tiene una propiedad determinada,

53 Nótese, en particular, que decir de algo que tiene "2 centímetros" de longitud supone ponerlo en relación con cierto patrón de medida que fija lo que ha de contar como un centímetro. Cuando se dice, entonces, que algo tiene 2 centímetros de longitud se está diciendo que posee una longitud que se encuentra en la relación 2:100 con la longitud del metro patrón.

${ }^{54}$ Cf. Bigelow \& Pargetter (1990, pp. 38-43, pp. 48-62).

Manuscrito - Rev. Int. Fil., Campinas, v. 34, n. 2, pp. 471-521, jul.-dez. 2011. 
automáticamente ha de poseer la propiedad determinable $\mathrm{y}$, correlativamente, explica porqué si algo tiene una propiedad determinable, ha de tener una propiedad determinada específica. Dado que algo instancia la propiedad de primer orden de, por ejemplo, tener 2 centímetros de longitud, entonces tiene la propiedad determinable de segundo orden de tener alguna propiedad de primer orden de tener cierta longitud (determinada), del mismo modo que todos los restantes objetos que tengan propiedades determinadas de tener cierta longitud. Los objetos con propiedades determinadas de tener cierta longitud habrán de encontrarse en relaciones de segundo orden de "ser de mayor longitud que" o de "ser de menor longitud que". Esto es, cuando un objeto instancia la propiedad de primer orden de tener 2 centímetros de longitud, entonces automáticamente instancia la relación de segundo orden de tener menor longitud que los objetos que instancien la propiedad de primer orden de, por ejemplo, tener 3 centímetros de longitud. Ahora bien, las relaciones de segundo orden (tener mayor longitud que, tener menor longitud que, tener la misma longitud que) caen bajo relaciones de tercer orden de poseer una diferencia de longitud de $n: m$. Cuando decimos que algo tiene 2 centímetros de longitud, entonces, le estamos atribuyendo la relación de tercer orden de tener una relación de 2:100 respecto del metro patrón, por el hecho de poseer una relación de segundo orden de tener menor longitud que el metro patrón, fundada -a su vez- en el hecho de que el objeto en cuestión tiene una propiedad de primer orden de longitud y que el metro patrón tiene una propiedad de primer orden de longitud.

En el caso de los universales estructurales, Bigelow y Pargetter también distinguen tres niveles ${ }^{55}$. Considérese el caso del metano $\mathrm{CH}_{4}$. Están las propiedades de primer nivel de ser un átomo de carbono, ser un átomo de hidrógeno y estar algo enlazado con algo. Están luego las relaciones de segundo orden de instanciar algo la propiedad de primer orden de ser un átomo de carbono, la relación de segundo orden de

${ }^{55}$ Cf. en especial Bigelow \& Pargetter (1990, p. 87).

Manuscrito - Rev. Int. Fil., Campinas, v. 34, n. 2, pp. 471-521, jul.-dez. 2011. 
instanciar algo la propiedad de primer orden de ser un átomo de hidrógeno y la relación de segundo orden de instanciar algo la relación de primer orden de estar algo enlazado con algo. Luego están las relaciones de tercer orden de encontrarse en la relación 4:1 las relaciones de segundo orden de instanciar algo la propiedad de primer orden de ser un átomo de carbono y la relación de segundo orden de instanciar algo la propiedad de primer orden de ser un átomo de hidrógeno. En esta misma relación se encuentran las relaciones de segundo orden de instanciar algo la propiedad de primer orden de ser un átomo de carbono y la relación de segundo orden de instanciar algo la relación de primer orden de estar algo enlazado con algo. Las relaciones de segundo orden de instanciar algo la propiedad de primer orden de ser un átomo de hidrógeno y la relación de instanciar algo la relación de primer orden de estar algo enlazado con algo se encuentran, por último, en la relación de tercer orden de estar en la relación 1:1. Tal como se puede ver, las relaciones de tercer orden "codifican" el hecho de que hay cuatro instanciaciones de la propiedad de primer orden de ser un átomo de hidrógeno, que hay cuatro instanciaciones de la relación de primer orden de estar algo enlazado con algo y que hay una instanciación de la propiedad de primer orden de ser un átomo de carbono.

La propuesta de Bigelow y Pargetter descansa en el hecho de que (i) la instanciación es una relación de segundo orden (que tiene como argumentos un objeto y un universal ${ }^{56}$ ) y (ii) que las propiedades de instanciación pueden encontrarse entre sí en relaciones de proporción. ¿Qué es aquí, entonces, la propiedad estructural de ser una molécula de metano? Pareciera consistir en el hecho de: (i) darse la relación de tercer orden de encontrarse en la proporción 4:1 las instanciaciones de la propiedad de ser hidrógeno y las instanciaciones

\footnotetext{
56 Por supuesto, también hay relaciones de instanciación de nivel superior. Por ejemplo, la relación de tercer orden de instanciaciar un universal una propiedad de segundo orden. Etcétera.
}

Manuscrito - Rev. Int. Fil., Campinas, v. 34, n. 2, pp. 471-521, jul.-dez. 2011. 
de la propiedad de ser carbono; (ii) darse la relación de tercer orden de encontrarse en la proporción 4:1 las instanciaciones de la relación de estar algo enlazado con algo y las instanciaciones de la propiedad de ser carbono; y (iii) darse la relación de tercer orden de encontrarse en la proporción 1:1 las instanciaciones de la relación de estar algo enlazado con algo y las instanciaciones de la propiedad de ser hidrógeno.

Esta propuesta, sin embargo, no es suficiente. Tiene dos problemas fundamentales. En primer lugar, pareciera que pudiesen instanciarse las tres relaciones de tercer orden indicadas y que no se instancie una molécula de metano. Si, por ejemplo, hay cuatro átomos de hidrógeno en un extremo del universo, un átomo de carbono en el extremo opuesto y cuatro enlaces químicos en el centro del universo, habrá una relación de 4:1 entre las relaciones de instanciación de la propiedad de primer orden de ser un átomo de hidrógeno y las relaciones de instanciación de la propiedad de primer orden de ser un átomo de carbono junto con las restantes relaciones de tercer orden indicadas. Difícilmente podría esto ser, sin embargo, una molécula de metano. Es indispensable que el universal estructural "codifique" el hecho de que son los mismos objetos que instancian la propiedad de ser hidrógeno o de ser carbono -según sea el caso- los que luego entran en la relación de estar algo enlazado con algo. Es indispensable también que se "codifique" que los mismos objetos que instancian estas propiedades conforman una suma mereológica a la que se atribuirá la propiedad estructural monádica. No es nada claro que Bigelow y Pargetter han asegurado estos requerimientos en su propuesta ${ }^{57}$.

\footnotetext{
57 Un indicio que parece apuntar en esta dirección es el hecho de que consideren las propiedades conjuntivas de "ser hidrógeno y ser parte de esta molécula” Bigelow y Pargetter (1990, p. 87). Quizás también estén pensando en propiedades conjuntivas de "ser hidrógeno y estar enlazado con un átomo de carbono" o algo semejante. No hay ninguna claridad, sin embargo, sobre cómo es que estas propiedades conjuntivas podrían codificar los hechos mereológicos y las "fusiones" de variables requeridos.
} 
En segundo lugar, todo lo que permiten codificar las relaciones de tercer orden indicadas es que hay cuatro instancias de ser un átomo de hidrógeno, hay cuatro instancias de la relación de estar algo enlazado con algo y una instancia de ser un átomo de carbono. ¿Qué sucede, sin embargo, con los casos en que existen moléculas diferentes con el mismo número de instancias? ¿Cómo se distinguen aquí, por ejemplo, las moléculas de butano y las moléculas de isobutano?

\subsection{Refinamientos de los universales de orden superior}

La cuestión es, entonces, rectificar y complementar la concepción de Bigelow y Pargetter de manera que puedan entregarse las estructuras requeridas. Esto es, se necesita alguna complexión de universales de orden superior, pero de tal modo que no sólo se pueda "codificar" el número de instanciaciones de cada universal más básico, sino que también puedan "codificarse" las identidades y diferencias de los diferentes objetos que instancian las propiedades y relaciones más básicas, así como también la estructura mereológica de tales objetos. Se ha considerado más arriba cómo mediante las "operaciones" de conjunción, reflexión, negación y universalización pueden "construirse" universales estructurales. El problema es que no queda claro qué han de ser semejantes "operaciones”. Una interpretación conjuntista -que es la usual para funciones y estructuras matemáticas- no sería de utilidad aquí. Deben tratar de hallarse universales de orden superior que puedan cumplir las mismas funciones de las operaciones indicadas.

Si filósofos como Armstrong han aceptado la existencia de universales conjuntivos, no debería haber demasiadas dificultades con aceptar algo semejante a una operación de conjunción de propiedades. También resultan necesarias, sin embargo, operaciones por las que se postula que hay partes propias de un objeto dado con cierta naturaleza intrínseca y con ciertas relaciones entre sí. Para esto serían suficientes las operaciones de universalización y negación, pues el resultado de las operaciones $\mathbf{N e g}\left(\mathbf{U n i v}_{\mathbf{1}}(\mathbf{N e g}(\mathrm{P}))\right)$ es la proposición de que hay al Manuscrito - Rev. Int. Fil., Campinas, v. 34, n. 2, pp. 471-521, jul.-dez. 2011. 
menos un $\mathrm{P}$, si es que $\mathrm{P}$ es monádica. Como este procedimiento requiere introducir la negación de una propiedad -algo rechazado con vehemencia por defensores de universales 'escasos'- será más económico postular la instanciación de una propiedad. Para quien quiera defender el libre funcionamiento de las operaciones indicadas arriba de negación, universalización, conjunción, reflexión, conversión e inserción, no habrá ningún inconveniente con el procedimiento que se sigue aquí, pues Univi podrá ser definido de la forma usual por la instanciación y la negación. Esto es, sea $\mathbf{I n s t}_{\mathbf{i}}(\mathrm{P})$ la operación por la que se cuantifica existencialmente la $i$-ava variable de $\mathrm{P}$ de tal manera que si $\mathrm{P}$ es $n$-ádica, entonces $\operatorname{Inst}_{\mathbf{i}}(\mathrm{P})$ es $(n-1)$-ádica. Entonces $\operatorname{Univ}_{\mathbf{i}}(\mathrm{P})=$ $\mathbf{N e g}\left(\operatorname{Inst}_{\mathbf{i}}(\mathbf{N e g}(\mathrm{P}))\right)$. La tercera pieza requerida es postular una propiedad de orden superior de reflexión por la que se fusionan variables de una propiedad. Si se admiten al menos estas tres propiedades de orden superior sobre otras propiedades se podrá generar toda la complexión requerida para los universales estructurales.

Pues bien, supónganse dos propiedad P y Q, siendo P n-ádica y Q $m$-ádica que se instancian en objetos. Si se aplica una operación de conjunción y resulta, por hipótesis, la propiedad $(n+m)$-ádica, sea $(\mathrm{P} \times$ Q $)^{58}$. ¿Esta propiedad también ha de ser instanciada en objetos? Pareciera que si $\mathrm{P}$ y $\mathrm{Q}$ son del primer nivel, $(\mathrm{P} \times \mathrm{Q})$ debería ser, por lo menos, de segundo nivel. Del mismo modo, si $\mathrm{P}$ es de primer nivel, la negación de $\mathrm{P}$ debería ser de segundo nivel. Las propiedades resultantes sin embargo, siguen siendo de primer nivel en el sentido de que se siguen instanciando en objetos. Usualmente se diferencia entre niveles o tipos de propiedades según si se instancian en objetos o en propiedades

\footnotetext{
${ }^{58}$ Se utilize esta numenclatura para diferenciar la operación de conjunción de $\mathrm{P}$ y $\mathrm{Q}$ de la operación booleana indicada arriba. La operación booleana $[\mathrm{P} \wedge \mathrm{Q}]$ arroja propiedad de instanciar al mismo tiempo $\mathrm{P}$ y $\mathrm{Q}$, mientras $[\mathrm{P} \times \mathrm{Q}]$ arroja la propiedad de estar algo instanciando $\mathrm{P}$ y estar algo instanciando $\mathrm{Q}$, sin que sea necesario que sean las mismas entidades las que instancian $P$ y las que instancian Q.
}

Manuscrito - Rev. Int. Fil., Campinas, v. 34, n. 2, pp. 471-521, jul.-dez. 2011. 
que se instancian en objetos, o en propiedades que se instancian en propiedades que se instancian en objetos, etcétera. Las propiedades de que aquí se trata, sin embargo, son 'de orden superior' en un sentido diferente. Se trata de cualificaciones en las propiedades de un modo análogo a como un adverbio, por ejemplo, cualifica semánticamente un predicado, sin hacer que el predicado deje de ser apto para aplicarse a sus sujetos gramaticales usuales. Si se cualifica, por ejemplo, el predicado "corre" por el adverbio "rápidamente", el resultado, "corre rápidamente" es tan aplicable a los sujetos usuales como lo es el predicado inicial sin cualificación. Del mismo modo, deben verse estas propiedades de orden superior como cualificaciones que introducen estructura en una propiedad, sin modificar el tipo de entidades en las que habría de instanciarse. Así, si $\mathrm{P}$ se instancia (o no) en objetos, también lo hará el resultado de $\mathbf{I n s t}_{\mathbf{i}}(\mathrm{P})$. Podrá modificar, si es el caso, la adicidad de $\mathrm{P}$, según el caso, pero esto es otra cuestión. Por ejemplo, si <Micifuz, Garfield> instancian la propiedad de [ $x_{1}$ golpea a $x_{2}$ ] (si existiese tal propiedad) y tanto Micifuz como Garfield son objetos,

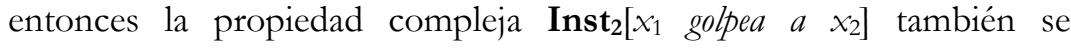
instanciará -si es que lo hace- en objetos. De hecho, como Micifuz está en la relación de golpear a Garfield, entonces Micifuz está en la relación de golpear a alguien.

¿Qué motivos existen para pensar que hay propiedades de orden superior tal como las requeridas? Pues bien, para empezar, hay una larga tradición que se remonta a Frege que concibe a los cuantificadores como propiedades de orden superior que atribuyen casos a una propiedad de primer orden ${ }^{59}$. Sin perjuicio de las funciones que puedan cumplir las expresiones lingüísticas que se utilicen en un lenguaje para cuantificar, puede pensarse en un universal de orden superior de "tener alguna instancia", esto es, "tener como instancia algún objeto u otro". Este es el recurso al que han hecho apelación, por lo demás, Bigelow y Pargetter, tal como se ha indicado. Para el caso de

${ }^{59}$ Cf. G. Frege, 1953, \53; 1972, pp. 21-45, especialmente pp. 38-45.

Manuscrito - Rev. Int. Fil., Campinas, v. 34, n. 2, pp. 471-521, jul.-dez. 2011. 
las conjunciones hay también una actitud en general de aceptación por parte de los defensores de universales 'escasos'. En general, sin embargo, el motivo fundamental para aceptar la existencia de estos universales de orden superior es la función teórica que cumplen para explicar la naturaleza de los universales estructurales. Según todo lo que sabemos, si se postula la existencia de universales, deben aceptarse universales estructurales. Por todo lo que sabemos, podrían ser todas las propiedades universales estructurales. No hay teorías alternativas que parezcan funcionar, tal como se ha explicado. Si los universales estructurales cumplen funciones explicativas que hacen aceptable su postulación y si universales de orden superior de conjunción, instanciación y reflexión son requeridos para explicar esa estructura, entonces hay también buenos motivos para aceptar los universales de orden superior que dan cuenta de tal estructura ${ }^{60}$.

$\mathrm{Si}$ existen, entonces, propiedades de segundo orden de conjunción, reflexión e instanciación, pueden darse universales estructurales como una complexión de universales de orden superior. El procedimiento general es el siguiente. En primer lugar se toman todos los universales de primer orden necesarios, entre los cuales ha de encontrarse la relación diádica de ser algo parte propia de algo $(\mathrm{x}<\mathrm{y}), \mathrm{y}$ se conectan mediante la relación de orden superior de conjunción. Considérese el ejemplo de agua $\mathrm{H}_{2} \mathrm{O}$ en que $\mathrm{H}$ es ser un átomo de hidrógeno, $\mathrm{O}$ es ser un átomo de oxígeno y $\mathrm{E}$ es estar algo enlazado con algo. Resulta: $\left.\left(\mathrm{x}_{12}<\mathrm{x}_{13}\right)\right)$

$\left(\mathrm{Ox}_{1} \times \mathrm{Hx}_{2} \times \mathrm{Hx}_{3} \times \mathrm{Ex}_{4} \mathrm{x}_{5} \times \mathrm{Ex}_{6} \mathrm{x}_{7} \times\left(\mathrm{x}_{8}<\mathrm{x}_{9}\right) \times\left(\mathrm{x}_{10}<\mathrm{x}_{11}\right) \times\right.$

${ }^{60}$ Una cuestión ulterior que no será considerada aquí es si deben admitirse libremente todas las estructuras que resulten de propiedades cumpliendo funciones análogas a las operaciones de negación, conjunción, reflexión, conversión, universalización e inserción. Para una defensa de esta posición, cf. Jubien, en Chierchia, Partee y Turner (989, pp. 159-175).

Manuscrito - Rev. Int. Fil., Campinas, v. 34, n. 2, pp. 471-521, jul.-dez. 2011. 
Esta propiedad de orden superior (14) es 13-ádica. Sobre (14) se aplica la propiedad de orden superior de reflexión para fusionar las variables que correspondan y obtener:

$$
\left(\mathrm{Ox}_{1} \times \mathrm{Hx}_{2} \times \mathrm{Hx}_{3} \times \mathrm{Ex}_{1} \mathrm{x}_{2} \times \mathrm{Ex}_{1} \mathrm{x}_{3} \times\left(\mathrm{x}_{1}<\mathrm{x}_{4}\right) \times\left(\mathrm{x}_{2}<\mathrm{x}_{4}\right) \times\left(\mathrm{x}_{3}\right.\right.
$$
$\left.\left.<\mathrm{x}_{4}\right)\right)$

Ahora se tiene una relación de orden superior tetrádica. Sobre esta relación tetrádica se debe aplicar la propiedad de orden superior de instanciación en las variables $\mathrm{x}_{1}, \mathrm{x}_{2} \mathrm{y} \mathrm{x}_{3}$. Resulta, entonces que:

(16) $\exists \mathrm{x}_{1} \exists \mathrm{x}_{2} \exists \mathrm{x}_{3}\left(\mathrm{Ox}_{1} \times \mathrm{Hx}_{2} \times \mathrm{Hx}_{3} \times \mathrm{Ex}_{1} \mathrm{x}_{2} \times \mathrm{Ex}_{1} \mathrm{x}_{3} \times\left(\mathrm{x}_{1}<\mathrm{x}_{4}\right) \times\left(\mathrm{x}_{2}\right.\right.$ $\left.\left.<\mathrm{x}_{4}\right) \times\left(\mathrm{x}_{3}<\mathrm{x}_{4}\right)\right)$

Ésta es exactamente la propiedad monádica de orden superior buscada, esto es, la propiedad de tener tres partes, una de las cuales es un átomo de oxígeno y dos de las cuales son átomos de hidrógeno, y en donde la primera está enlazada con la segunda y con la tercera. Esta propiedad (16) puede ser expresada mediante el predicado: $\wedge$ Eyv]

Si hay propiedades de orden superior para las operaciones de conjunción, instanciación y reflexión, parece razonable pensar que existen todas las estructuras con las que la ciencia natural nos familiariza diariamente.

\section{6. ¿No es esto magia?}

La propuesta presentada podría ser inmediatamente objetada como un "truco de magia". Pareciera, podría sostener el crítico, que se han Manuscrito - Rev. Int. Fil., Campinas, v. 34, n. 2, pp. 471-521, jul.-dez. 2011. 
inventado todas las propiedades de orden superior necesarias para construir propiedades estructurales, replicando las misteriosas "operaciones". Sin una justificación independiente de la existencia de los universales de negación, conjunción, reflexión, universalización y etcétera, su postulación parece sencillamente ad hoc. Aquí se ha pretendido eliminar la "magia" de conexiones necesarias entre diferentes universales mediante la introducción de unas entidades "mediadoras" que son tan "mágicas" como la conexión que pretenden explicar.

Para contestar esta alegación debe destacarse, en primer término, que una entidad merece el calificativo de "mágica" o una conexión entre entidades merece el calificativo de "mágica" si es que, en términos generales, esa entidad o esa conexión entre entidades aparece en violación de un background de creencias sobre qué naturaleza debe tener una entidad existente y sobre qué conexiones son permisibles entre entidades diferentes. Sólo contra el fondo de esas creencias es que algo puede chocar como una intromisión de "magia" para la que no se posee explicación. Cuando Lewis califica la composición de propiedades con otras propiedades como "mágica" lo hace contra la suposición de que toda forma de composición o es mereológica o es conjuntista. Es poco lo que se puede hacer contra esto, pues sólo podría disiparse la desconfianza de un filósofo como Lewis si es que se mostrase que los universales estructurales son, después de todo, construcciones conjuntistas o mereológicas. No lo son, sin embargo. La forma de disipar la sensación de "magia" aquí es mediante la transformación de ese background de creencias sobre qué conexiones pueden darse entre entidades, mostrando una concepción ontológica general que haga esperable la composición de universales por otros universales.

Esto es exactamente lo que se ha hecho aquí. Hay universales. Hay universales de orden superior. Un universal estructural es un universal compuesto de otros universales. Su forma de composición debería depender de universales de orden superior. ¿Cuáles? 
Precisamente universales que corresponden a las "operaciones" descritas en las teorías formales de propiedades. No es causalidad que esas teorías hayan sido formuladas con relativa coincidencia por diferentes investigadores. Lo que es de esperarse es que las propiedades de orden superior que se buscan estén en correlación con las formas de "construcción" que han sido ya descritas. Y esto es lo que se ha propuesto, precisamente. Por supuesto, si algún filósofo rechaza la existencia de universales o rechaza la postulación de universales de orden superior entonces la solución propuesta aquí le parecerá poco verosímil. Pero eso es algo que merece una discusión larga y separada. Para un filósofo que sí acepta universales y que sí acepta universales que han de ejemplificarse dado que algo instancia otros universales, se ha entregado una explicación verosímil. No hay magia aquí, porque los universales no son magia.

\section{Conclusiones}

Se ha presentado en este trabajo, en primer lugar, el concepto de universal estructural, mostrando su conexión con otras nociones cercanas como universal complejo y universal anhomeomérico. Un universal estructural es un universal que es instanciado en un objeto porque las partes propias de ese objeto instancian, a su vez, determinadas propiedades intrínsecas y se encuentran entre sí en determinadas relaciones. Esto es, un universal estructural requiere: (i) ciertos objetos que conforman una suma mereológica, (ii) una naturaleza intrínseca para estos objetos, y (iii) relaciones entre estos objetos (que pueden ser, en algunos casos, triviales o meramente mereológicas). La propiedad estructural superviene a esta base en que se encuentra ontológicamente fundada.

La noción de universal estructural, sin embargo, ha encontrado fuertes críticas. Por un lado, filósofos como Mellor han sostenido que no hay justificación suficiente para su postulación (aún aceptando la existencia de universales) porque los universales estructurales pueden 
eliminarse a favor de los universales básicos que lo componen. Por otro lado, filósofos como David Lewis han exigido que se explique en qué consiste la composición en virtud de la cual diferentes universales pueden llegar a conformar un universal diferente. Las formas de composición usual de tipo conjuntista o mereológica no son adecuadas para los universales estructurales. Faltando una explicación adecuada, la idea de un universal estructural debería tenerse como ininteligible.

Se ha argumentado aquí que el test de Ramsey propuesto por Mellor para determinar qué universales existen no lleva a suprimir los universales estructurales y complejos de nuestra ontología. Se han discutido, después, las diversas estrategias que han sido ensayadas para explicar la naturaleza de los universales estructurales, incluyendo las operaciones usualmente postuladas en las teorías formales de propiedades, los tipos de estados de cosas postulados por Armstrong, las relaciones formales postuladas por Pagès y los universales de orden superior postulados por Bigelow y Pargetter. Una vez explicadas las dificultades y limitaciones que estas diferentes alternativas presentan, se ha defendido una explicación en la que los universales estructurales surgen por la complexión de universales de orden superior y que corresponden con las "operaciones" descritas en las teorías formales, tal como era de esperar. En el contexto de una ontología que acepta la existencia de universales y acepta también la existencia de jerarquías de universales de diferente orden, la existencia de universales estructurales es perfectamente verosímil ${ }^{61}$.

${ }^{61}$ Este trabajo ha sido redactado en ejecución del proyecto de investigación Fondecyt 1070339 (Conicyt, Chile). Agradezco los útiles comentarios de un evaluador anónimo de esta revista.

Manuscrito - Rev. Int. Fil., Campinas, v. 34, n. 2, pp. 471-521, jul.-dez. 2011. 


\section{REFERENCIAS BILIOGRÁFICAS}

ALVARADO, J. T. “¿Qué es el espacio ontológico modal?”. Philosophica 29, pp. 7-44, 2006.

ARMSTRONG, D. M. A Theory of Universals, Volume II: Universals and Scientific Realism. Cambridge: Cambridge U.P., 1978.

1983.

What is a Law of Nature? Cambridge: Cambridge U.P.,

. "In Defence of Structural Universals". Australasian Journal of Philosophy, 64, pp. 85-88, 1986.

Westview, 1989.

- A W orld of States of Affairs. Cambridge: Cambridge U.P., 1997.

BIGELOW, J. \& PARGETTER, R. Science and Necessity. Cambridge: Cambridge U.P., 1990.

-. "A Theory of Structural Universals". Australasian Journal of Philosophy 67, pp. 1-11, 1989.

BROAD, C. D. "Mechanism and Emergentism". In Kim and Sosa, (eds) (1999), pp. 487-498.

CHIERCHIA, G; PARTEE, B.; TURNER, R. (eds). Properties, Types and Meaning, Volume I: Foundational Issues. Dordrecht: Kluwer, 1989.

DRETSKE, F. “Laws of Nature”. Philosophy of Science, 44, pp. 248268, 1977.

FREGE, G. Die Grundlagen der Arithmetik. 1884. Trans. by J. L. Austin, The Foundations of Arithmetic. Oxford: Blackwell, 1953. 
FORREST, P. "Ways Worlds Could Be". Australasian Journal of Philosophy, 64, pp. 15-24, 1986a.

"Neither Magic Nor Mereology: A Reply to Lewis", Australasian Journal of Philosophy, 64, pp. 89-91, 1986b.

van INWAGEN, P. Material Beings. Ithaca: Cornell U.P., 1990.

JUBIEN, M. "On Properties and Property Theory". In G. Chierchia, B. Partee y R. Turner (eds) (1989), pp. 159-175.

KIM, J. "Concepts of Supervenience". Supervenience and Mind. Selected Philosophical Essays, pp. 53-78. Cambridge: Cambridge U.P., 1993.

. “'Strong' and 'Global' Supervenience Revisited”. Supervenience and Mind. Selected Philosophical Essays, pp. 79-91. Cambridge: Cambridge U.P., 1993.

KIM, J.; SOSA, E. (eds). Metaphysics. An Anthology. Blackwell, 1999.

LEWIS, D.. On the Plurality of Worlds. Oxford: Blackwell, 1986.

Papers in Metaphysics and Epistemology. Cambridge: Cambridge U.P., 1999.

78-107.

“Against Structural Universals". In: D. Lewis (1999), pp.

"New work for a Theory of Universals". In: D. Lewis (1999), pp. 8-53.

MELLOR, D.H. The Facts of Causation, London: Routledge, 1995.

PAGÈS, J. "Structural Universals and Formal Relations", Synthese 131, 215-221, 2002.

POTTER, M. Set Theory and its Philosophy. Oxford: Oxford U.P., 2004.

PUTNAM, H. "On Properties", en J. Kim \& E. Sosa (eds.) (1999), pp. 243-252. 
QUINE, W. V. O. Desde un punto de vista lógico. Barcelona: Orbis, 1984. 24-47.

. "Acerca de lo que hay”. In W. V. O. Quine (1984), pp.

RAMSEY, F. P. Los fundamentos de la matemática y otros ensayos de lógica. Santiago: Ediciones de la Universidad de Chile, 1968. . “Teorías”. In F. P. Ramsey (1968), pp. 199-221.

SHOEMAKER, S. "Causality and Properties". In Identity, Cause, and Mind, pp. 206-233. Oxford: Clarendon Press, 2003. pp. 206-233.

SIMONS, P. Parts. A Study in Ontology. Oxford: Clarendon Press, 1987

STALNAKER, R. Ways a World Might Be. Metaphysical and AntiMetaphysical Essays. Oxford: Clarendon Press, 2003.

—. "Possible Worlds". In: R. Stalnaker, (2003), pp. 25-39.

SWOYER, C. "Complex Predicates and Logics for Properties and Relations". Journal of Philosophical Logic, 27, pp. 295-325, 1998.

TOOLEY, M. "The Nature of Laws". Canadian Journal of Philosophy, 7, pp. 667-698, 1977. 1987.

THOMASSON, A. Ordinary Objects. Oxford: Oxford U.P., 2007. 